\title{
A scoping review of inequities in access to organ transplant in the United States
}

\author{
Christine Park' , Mandisa-Maia Jones², Samantha Kaplan³, Felicitas L. Koller ${ }^{4}$, Julius M. Wilder ${ }^{5}$, \\ L. Ebony Boulware ${ }^{6}$ and Lisa M. McElroy ${ }^{1 *}$ (1)
}

\begin{abstract}
Background: Organ transplant is the preferred treatment for end-stage organ disease, yet the majority of patients with end-stage organ disease are never placed on the transplant waiting list. Limited access to the transplant waiting list combined with the scarcity of the organ pool result in over 100,000 deaths annually in the United States. Patients face unique barriers to referral and acceptance for organ transplant based on social determinants of health, and patients from disenfranchised groups suffer from disproportionately lower rates of transplantation. Our objective was to review the literature describing disparities in access to organ transplantation based on social determinants of health to integrate the existing knowledge and guide future research.

Methods: We conducted a scoping review of the literature reporting disparities in access to heart, lung, liver, pancreas and kidney transplantation based on social determinants of health (race, income, education, geography, insurance status, health literacy and engagement). Included studies were categorized based on steps along the transplant care continuum: referral for transplant, transplant evaluation and selection, living donor identification/evaluation, and waitlist outcomes.
\end{abstract}

Results: Our search generated 16,643 studies, of which 227 were included in our final review. Of these, 34 focused on disparities in referral for transplantation among patients with chronic organ disease, 82 on transplant selection processes, 50 on living donors, and 61 on waitlist management. In total, 15 studies involved the thoracic organs (heart, lung), 209 involved the abdominal organs (kidney, liver, pancreas), and three involved multiple organs. Racial and ethnic minorities, women, and patients in lower socioeconomic status groups were less likely to be referred, evaluated, and added to the waiting list for organ transplant. The quality of the data describing these disparities across the transplant literature was variable and overwhelmingly focused on kidney transplant.

Conclusions: This review contextualizes the quality of the data, identifies seminal work by organ, and reports gaps in the literature where future research on disparities in organ transplantation should focus. Future work should investigate the association of social determinants of health with access to the organ transplant waiting list, with a focus on prospective analyses that assess interventions to improve health equity.

Keywords: Organ transplant, Inequities, Disparities, Access

*Correspondence: lisa.mcelroy@duke.edu

${ }^{1}$ Division of Abdominal Transplant, Department of Surgery, Duke University School of Medicine, Durham, NC, USA

Full list of author information is available at the end of the article

\section{Background}

Transplantation has been a durable treatment option for patients with end-stage organ disease for over 40 years, with over 30,000 organ transplants performed in the United States (US) in 2019 [1]. Disparities in transplantation affect every organ and span the continuum of transplant care, from referral to postoperative outcomes. Yet, 
despite several decades of research on disparities in organ transplant, causal mechanisms between social determinants of health and inequities in access to transplant have not been clearly established. It is also unclear if previously developed interventions have resulted in sustained reduction in disparities for disenfranchised groups. We performed a scoping review of the literature for US-based studies that described disparities or identified sources of health inequities along the continuum of transplant care. We hypothesized that most research describing disparities and health inequities in transplant is (1) focused on patients after addition to the organ transplant waitlist, and (2) focused on kidney transplant. We also hypothesized that most research aimed at understanding the influence of social determinants of health on access to transplant is limited to race, gender and insurance status.

\section{Methods}

The research question we aimed to address in this scoping review was: How many US-based studies have quantified disparities or identified sources of health inequities in adults during the transplant selection process (referral, evaluation and selection, living donation, waitlist)? We chose a scoping review due to the broad scope and our intended purpose of identifying the types of evidence available in this area and the gaps in the knowledge base [2].

A medical librarian with expertise in systematic searching (SK) composed a search utilizing a combination of subject headings and keywords to represent the concepts of socioeconomic status, race, organ disease or failure, organ transplantation, and delivery of health care. The databases used were MEDLINE via PubMed, Embase via Elsevier, the Cumulative Index to Nursing and Allied Health Literature Complete via EBSCO, and the Web of Science Core Collection via Clarivate, with a search from journal inception until November 27, 2019. A search update was run on April 20, 2021.

Our inclusion criteria consisted of 1) United States based studies available in English of adults during the selection process or on the waitlist for kidney, liver, pancreas, heart or lung transplant and 2) studies that associate one or more social determinants of health with transplant selection process or waitlist outcomes. We excluded studies that were based outside of the US, not available in English, studies not reporting primary or secondary data (e.g. editorials, opinion pieces and review articles), studies focused on assessment of deceased donor organs, and studies focused on disparities related to a single diagnosis (e.g. sickle cell disease).

All references were compiled in EndNote and imported into Covidence systematic review software (Veritas Health Innovation, Melbourne, Australia. Available at www.covid ence.org) for deduplication and screening. When databases allowed for it, non-human studies, editorials, case reports, and conference abstracts were removed. All search strategies are available in the appendix (Additional file 1).

Studies were screened by five investigators (CP, JW, FK, MJ, LM) after an initial study team meeting to discuss the purpose of the review and define the inclusion and exclusion criteria. Full texts were screened by three authors (CP, MJ, LM). Disagreements in screening and were resolved via consensus after discussion.

\section{Results}

In total, 227 studies were identified (Fig. 1), all of which were all performed in the US and published between the years 1992 and 2021. Of these, 35 focused on disparities in referral for transplantation among patients with chronic organ disease, 82 focused on transplant selection processes, 50 on living donors, and 60 on waitlist management; 15 studies involved the thoracic organs (heart, lung), 209 involved the abdominal organs (kidney, liver, pancreas), and three involved both thoracic and abdominal organs (Table 1). There was a total of 13 clinical trials, 8 of which examined racial equity in living donor kidney transplant. Fifteen studies used national transplant registry data (Scientific Registry of Transplant Recipients (SRTR) or United States Renal Data System (USRDS).

\section{Referral of patients with chronic organ disease for transplantation \\ Thoracic}

Two studies examined referral of patients with heart failure for advanced therapies, including transplantation A retrospective analysis of the National Inpatient Sample by Thakkar et al. found a lower rate of device utilization and referral for heart transplantation among Medicaid recipients compared to privately-insured patients [3]. Breathett et al. expanded on this association with a qualitative study of transplant clinicians which demonstrated significant reliance on perceptions about the adequacy of social support for women as part of overall candidacy for advanced heart therapies. Specifically, children were perceived as liabilities for women, and family dynamics and finances were perceived to be of greater importance when spouses were deemed to be inadequate supports for the women [4].

\section{Abdominal}

Kidney Two clinical trials have tested educational interventions to improve equity in referral for kidney transplant

The Reducing Disparities in Access to kidNey Transplantation (RaDIANT) Community Study was a dialysis 


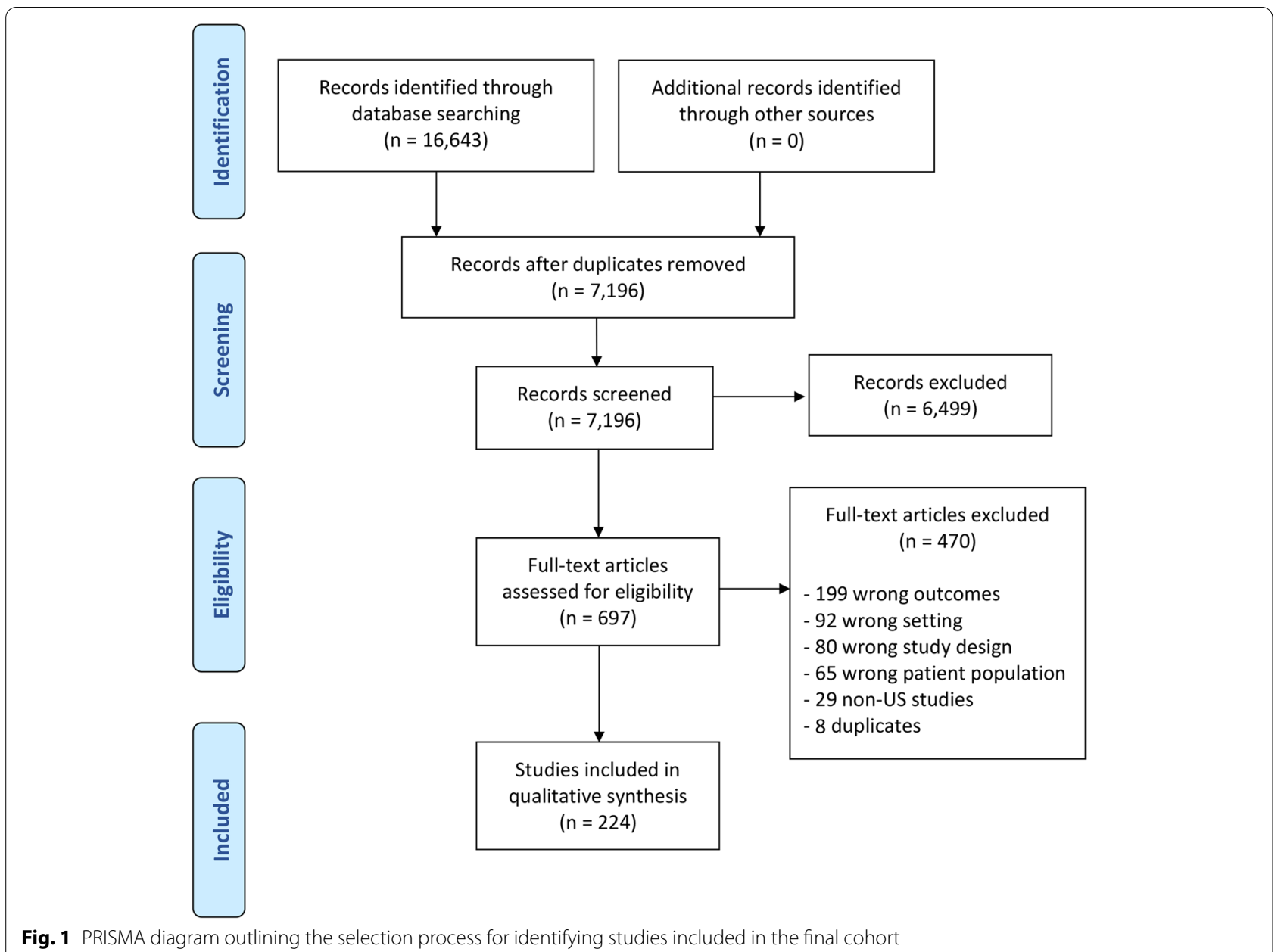

facility-based, randomized clinical trial conducted in 2014 to test the effectiveness of a multicomponent intervention aimed at increasing referral for kidney transplantation in Black patients. The intervention consisted of education and outreach activities for dialysis facility leadership, staff, and patients $[5,6]$. The intervention increased the proportion of patients referred for transplant at 12 months (adjusted mean difference of 7.3\%) and the difference between intervention and control facilities was greater among Black vs White patients (adjusted mean difference of $6.4 \%$ vs $3.4 \%$ ) [7].

The Explore Transplant at Home study was a prospective parallel-arm, randomized controlled trial that compared the effect of educational interventions on patients' knowledge of transplant. The intervention arms were: (1) transplantation education provided in dialysis centers only (standard of care), (2) a patient-guided Explore Transplant at Home program, and (3) the Explore Transplant at Home program facilitated by a telephonic educator [8]. Patients' knowledge of transplant as assessed by a postintervention survey using the transplantation knowledge scale showed increased likelihood of transplant evaluation initiation versus control groups ( $38 \%$ vs $24 \%$, $P=.006$ ) [9]. The number of discrete, new steps taken by those in the patient-guided program group was also higher than in the control group (incident rate ratio, 1.21; 95\% confidence interval $[\mathrm{CI}], 1.01-1.47 ; P=.04)$, but there was no difference between the educator-guided and control groups [10].

Three retrospective analyses of national data have described inequities in referral for kidney transplant

Both studies used the USRDS to examine the timing of transplant referral. Inclusion of the race coefficient in the Chronic Kidney Disease Epidemiology Collaboration (CKD-EPI) study's estimation of glomerular filtration 
Table 1 Summary of the included studies stratified by study category and organ types

\begin{tabular}{|c|c|c|c|c|c|}
\hline & Referral & Evaluation and listing & Living donor & Waitlist outcomes & Total \\
\hline \multicolumn{6}{|l|}{ Mixed solid organs } \\
\hline Prospective & - & - & - & - & - \\
\hline Retrospective & - & 3 & - & - & 3 \\
\hline Clinician survey & - & - & - & - & - \\
\hline Patient survey & - & - & - & - & - \\
\hline \multicolumn{6}{|l|}{ Thoracic organs } \\
\hline Heart & 2 & 5 & - & 8 & 15 \\
\hline Prospective & - & 1 & - & - & 1 \\
\hline Retrospective & 2 & 3 & - & 8 & 13 \\
\hline Clinician survey & - & 1 & - & - & 1 \\
\hline Patient survey & - & - & - & - & - \\
\hline Lung & - & - & - & - & - \\
\hline \multicolumn{6}{|l|}{ Abdominal organs } \\
\hline Kidney & 29 & 61 & 49 & 24 & 163 \\
\hline Prospective & 6 & 9 & 17 & 1 & 33 \\
\hline Retrospective & 8 & 39 & 17 & 20 & 84 \\
\hline Clinician survey & 6 & 3 & 3 & - & 12 \\
\hline Patient survey & 9 & 10 & 12 & 3 & 34 \\
\hline Liver & 3 & 11 & 3 & 28 & 45 \\
\hline Prospective & - & 2 & - & 2 & 4 \\
\hline Retrospective & 3 & 8 & 3 & 25 & 39 \\
\hline Clinician survey & - & - & - & - & - \\
\hline Patient survey & - & 1 & - & 1 & 2 \\
\hline Pancreas & - & 2 & - & - & 2 \\
\hline Prospective & - & - & - & - & - \\
\hline Retrospective & - & 2 & - & - & 2 \\
\hline Clinician survey & - & - & - & - & - \\
\hline Patient survey & - & - & - & - & - \\
\hline Total & 34 & 82 & 52 & 60 & 228 \\
\hline
\end{tabular}

rate (GFR) was examined by Zelnick et al. with the goal of determining the impact on eligibility for transplant. The CKD-EPI formula was found to overestimate GFR by a mean of $3.1 \mathrm{~mL} / \mathrm{min} / 1.73 \mathrm{~m}^{2}$ (95\% CI $2.2-3.9 \mathrm{~mL} /$ $\left.\mathrm{min} / 1.73 \mathrm{~m}^{2} ; P<.001\right)$ [11]. This error in estimate was associated with a $35 \%$ (95\% CI 29-41\%) higher risk of achieving an eGFR less than $20 \mathrm{~mL} / \mathrm{min} / 1.73 \mathrm{~m}^{2}$ and a shorter median time to transplant eligibility by 1.9 years. Kucirka et al. found that a significant proportion of patients had not received information about the option of transplant at the time of dialysis initiation, most commonly due to lack of clinician assessment. Notably, patients with advanced age, obesity, public or no insurance and at for-profit centers were less likely to be assessed [12]. Despite being less likely to receive transplant education, Black and Hispanic patients had a lower prevalence of medical barriers to transplantation than White patients at the time of dialysis initiation [13].
Five regional/single-center studies have described inequities in referral for kidney transplant

Lack of formal education, minority race, Hispanic ethnicity and female gender were all negatively associated with referral to a transplant center [14-17]. A single center study of the impact of the race coefficient in the CKD-EPI eGFR equation showed one-third of patients could be reclassified to a more severe CKD stage if the race multiplier were removed, and $3.1 \%$ of patients would newly qualify for accumulating kidney transplant priority [18].

\section{Six studies surveyed clinicians for their perceptions of inequities in referral for kidney transplant}

Referring nephrologists and dialysis staff both demonstrated knowledge deficiencies, including lack of 
experience with or recognition of gender and racial disparities in access to kidney transplant [19, 20]. Nephrologists reported being less likely to believe that transplantation prolongs survival relative to dialysis for Black patients in comparison to White patients and differences in referral for renal transplantation arise from differences in patients' preferences rather than from problems with communication, trust, or racial bias that may relate to physicians' actions or inaction [21]. Despite acknowledgment of the importance of education, nephrologists treating predominantly Black, elderly, and Medicaidinsured patients have reported insufficient time as the primary barrier to transplant education [22]. Furthermore, surveyed clinicians reported increased referral of patients with high school or greater education. Patients less likely to be referred included homemakers and other unemployed patients compared with employed patients [23]. Low socioeconomic status and age were identified as the primary drivers of racial disparities in rates of referral. Dialysis center characteristics associated with lower odds of recommending transplant included those in rural locations, with for-profit ownership, and with greater percentages of uninsured patients and/or more patients older than age 65 [24].

Nine studies surveyed patients for their perceptions of inequities in referral for kidney transplant

Black patients and women reported lower rates of referral and later referral for transplantation, poor treatment by medical professionals, and poor education about renal disease and treatment options [25-27]. Concerns about pursuing kidney transplant included increased medication burden, fear of surgery, and fear of organ rejection [28]. Barriers to initiating transplant evaluation included confusion about diagnosis, lack of transplant knowledge, financial burdens, transportation, scheduling, emotional overload of chronic illness, medical mistrust, experiences with discrimination, and perceived racism $[29,30]$. Lack of knowledge about transplantation and insufficient patient-clinician communication were cited as persistent barriers to transplant, even in a setting of strong social support, high self-reported interest, and adequate insurance coverage [25, 31-33].

\section{Liver Three studies have described inequities in referral for liver transplant}

In a Veterans Administration (VA)-based study, liver transplantation was considered for only $21 \%$ of patients satisfying referral guidelines from the American Association for the Study of Liver Disease. Negative determinants were older age, presence of alcoholic liver disease, and
Black race [34]. Two additional studies that used the SRTR data reported that patients of female gender, Black race, and Medicare insurance were less likely to be referred and evaluated for liver transplantation [35]. Of those referred, Black patients had a higher likelihood of residing closer to the transplant center and having a higher Model for EndStage Liver Disease (MELD) score at presentation [36].

\section{Transplant center selection processes Non-organ specific}

Three studies investigated inequities in the transplant selection process for all solid organs

In a study of all solid organ transplant candidates, patients living in rural areas had a lower rate of waitlisting and transplant despite equivalent outcomes following transplant, suggesting barriers to evaluation and waitlist entry for rural residents with organ failure [37]. Patients with limited reading or math ability and patients with cognitive impairment were also less likely to be listed for transplant and more likely to be removed from listing or to miss prelisting appointments [38]. For all organs except liver, the number of transplants performed among Medicaid beneficiaries was only half of the expected number based on the Medicaid-insured population. Medicaid transplant recipients were listed with more severe organ failure, suggesting a longer time to successfully complete the evaluation process [39].

\section{Thoracic}

Heart Five studies (one prospective, three retrospectives, one clinician survey) investigated inequities in the transplant selection process for heart failure patients

These studies demonstrated that age, gender, income, insurance status and race all influence decision-making for advanced heart failure therapies, with patients who are over age 40, female, and Black less likely to be selected for transplant [40]. Patient adherence and social history both were found to weigh heavily on clinician decision-making [41, 42]. Medicare and Medicaid insurance predicted lower odds of both left ventricular assist device (LVAD) and eligibility for heart transplant [43]. However, Medicaid expansion resulted in a $30 \%$ increase in the rate of heart transplant listings for Black patients in early adopter states [44].

\section{Abdominal}

Kidney Three clinical trials tested interventions to decrease disparities in completion of the transplant selection process and approval for the kidney transplant waitlist 
A randomized controlled trial that aimed to test the effectiveness of trained navigator assistance in the process of referral to selection committee decision found an increase in waitlisting (primary outcome) and a reduction in time from referral to waitlisting (secondary outcome) [45]. The study did not demonstrate significant difference in the listing rate between patients in the control and intervention groups. Time from referral to waitlisting was 126 days longer for patients in the intervention group, and these patients were 3.3 times more likely than patients in the control group to be waitlisted after 500 days $(75 \%$ vs $25 \%$; hazard ratio, 3.31; 95\% CI 1.20-9.12).

The iChoose Kidney study was a randomized controlled trial to test the clinical efficacy of an electronic application designed to educate patients about the survival benefit of kidney transplantation. The primary outcome was change in knowledge about the survival benefit of kidney transplantation vs dialysis [46]. Change in knowledge as assessed by survey was greater among intervention $(1.1 \pm 2.0)$ vs control $(0.4 \pm 1.8)$ patients $(P<.0001)$. However, access to transplantation was similar [47].

The Allocation System Changes for Equity in Kidney Transplantation (ASCENT) trial is an ongoing randomized controlled effectiveness-implementation study designed to test the effectiveness of a multicomponent intervention to improve access to the early steps of kidney transplantation among dialysis facilities across the United States (US). The intervention consisted of an educational webinar for dialysis medical directors, educational videos for patients and dialysis staff, and a dialysis facility-specific transplantation performance feedback report. There was minimal difference between the intervention and control groups for the primary outcomes (change in proportion of patients waitlisted, and disparity reduction in proportion of patients waitlisted in a dialysis facility after 1 year) [48].

\section{Five studies prospectively assessed inequities in the kidney transplant selection process}

Both race and gender have been independently associated with decreased likelihood of completing the evaluation process, with significant interaction between race and income as well as gender and income $[49,50]$. Black patients were found to be $25 \%$ less likely ( $95 \%$ CI $0.60-0.96)$ to be waitlisted than White patients even after adjusting for medical factors and other social determinants of health. Advanced age, low income, public insurance, comorbidities, and dialysis status also decreased the probability of waitlisting. On the other hand, increased social support and transplant knowledge increased the probability of waitlisting [51]. Failure to complete the selection process was more commonly caused by remaining stationary rather than moving backward in the process or dying [52]. Educational sessions increased the one-year evaluation completion rates (adjusted risk ratio of completion at 1 year $=1.38,95 \%$ CI $1.12-1.71$ ), particularly among Black patients and patients living in nonaffluent neighborhoods [53].

Twenty-one retrospective studies of national data registries examined disparities in completion of the transplant selection process and approval for the kidney transplant waitlist

Studies using the United Network for Organ Sharing (UNOS) data have demonstrated low rates of addition to the waitlist for Black and female patients on dialysis [54, 55]. Low rates of preemptive listing and prolonged exposure to prelisting dialysis were associated with Medicare insurance, minority race/ethnicity, low educational attainment, longer distance to transplant center, and residence in distressed communities [56, 57].

Studies using the USRDS data have demonstrated low rates of addition to the waitlist among women, minorities, patients receiving dialysis at facilities located further away from transplant centers, and the elderly [58-60]. Among UNOS regions, racial disparities appear to be more pronounced where Black patients comprise a large proportion of the end stage renal disease (ESRD) population [61]. Factors shown to mitigate these characteristics included education, social support, and employment [62-68]. Interestingly, early referral to a nephrologist has been shown to increase the likelihood of successful completion of the process [69]. State Medicaid coverage seemed to mediate both the incidence of ESRD and insurance-related differences in access [70].

Studies combining the USRDS and the UNOS databases have allowed for examination of the influence of comorbidity profile and dialysis vintage on access to the transplant waitlist. These studies reinforce prior knowledge of decreased likelihood of waitlisting and transplant among minorities, the impoverished, and the elderly [71-73]. Implementation of the kidney allocation system (KAS) in 2014 has reduced inactive waitlisting among minorities and has contributed to reduced racial disparity [74].

Eighteen retrospective analyses of regional and singlecenter data have identified disparities in completion of the kidney transplant selection process 
These studies largely reinforced the findings of national analyses: that female gender, advanced age, non-White race, low educational level, low income, and Medicaid insurance are associated with decreased rates of listing for transplant and increased waitlist mortality [75-91]. The extent of patient support networks and provision of enhanced educational sessions at the time of referral for renal transplant are associated with increased completion of the evaluation process [92].

\section{Three studies surveyed clinicians for their perceptions of inequities in the kidney transplant selection process}

Clinician-reported impressions of patient barriers to transplant included negative personal behaviors such as individual irresponsibility and lack of self-management of comorbidities as well as limited income, transportation difficulties, insurance issues, and limited/lack of social support. Furthermore, clinicians reported believing that patients are largely responsible for the development of ESRD, and increased social responsibility was needed to improve poor health status and disparities in kidney transplantation rates [93]. When assessing personal responsibility and self-management as part of candidacy determination, clinicians included assessing adherence but used proxies such as the number of missed hemodialysis sessions, therapeutic drug levels, and the Simplified Medication Adherence Questionnaire [94]. Educational barriers were also identified by providers which included difficulty accessing information about transplantation, limited knowledge of transplantation, lack of formal education with associated literacy and/or reading comprehension challenges. Providers also identified systemic barriers such as scheduling difficulties, late or delayed referrals for transplant, poor patient-staff communication, and limited access to transplant coordinators [95].

Ten studies reported patient perspectives on barriers to completion of the kidney transplant selection process

Surveyed patients echo the findings of national analyses: that early transplant awareness promotes engagement in the transplant subsequent waitlisting and the impact is more pronounced in White vs Black patients [96]. Evaluation completion is less likely in patients who were previously evaluated at a different transplant center as well as patients already on dialysis at the time of referral with the financial burden of kidney transplantation being a prominent deterrent [97].

Minority patients also reported low rates of transplant education and a high level of misinformation about the different stages in the evaluation process, with common misbeliefs being that dialysis must precede transplantation and that transplantation is only available as a last resort [98-101]. A significant number of patients undergoing evaluation for transplant remained unaware of their listing status, including mistakenly believing they were already on the waitlist [102].

The reasons for patients declining transplant were commonly due to negative personal experience with previous transplant and/or hearing about another patient's negative experience [103]. Other prominent patient-reported barriers to transplant included financial concerns and poor communication [98, 104]. Barriers were most prominent in racial/ethnic minorities and people with low income. Black patients were more likely than White patients to report racial discrimination, and women were more likely than men to report gender discrimination during the evaluation and selection process [105].

\section{Liver Two studies prospectively assessed inequities in the liver transplant selection process}

A prospective assessment of liver candidate literacy revealed that low health literacy was independently associated with not being waitlisted for transplant, although the effect was attenuated by strong social support [106]. A national assessment of transplant center websites examined disparities in access to the waitlist using the Website Clear Communication Index and demonstrated that each point increase in the index score (signaling improved communication) was associated with a $0.2 \%$ increase in waitlisting of low educational attainment patients [107].

Three retrospective analyses of national data described inequities in the liver transplant selection process

All studies used the UNOS database and found increased rates of medical unsuitability for transplantation, death during the evaluation process, and waitlist mortality among racial minority patients [108-110]. Although time spent on waitlists was similar, Black race negatively affected outcomes while awaiting liver transplant.

\section{Five regional or single-center studies examined ineq- uities in the liver transplant selection process}

These studies echoed the findings of larger studies, demonstrating association of minority status with lower odds of being listed and a longer time to selection committee decision compared to other patients, even after adjusting for socioeconomic factors $[111,112]$. Black patients with 
hepatocellular carcinoma were less likely to undergo liver transplantation than White patients, and substance abuse was more frequently cited as the reason Black patients within the Milan criteria failed to undergo transplantation compared to White patients [113]. Successful listing for liver transplant was also associated with private insurance and access to a local gastroenterologist [114]. A study of the effects of telehealth on the liver transplant selection process found a reduction in the time from referral to evaluation and listing, but not to transplantation [115].

A single study reported patient perspectives about inequities in the liver transplant selection process

All patients reported wanting liver transplant if recommended. Compared with non-listed patients, waitlisted patients had attained higher education levels and were more likely to be privately-insured [116]. Non-listed patients were significantly less likely to have discussed liver transplant with their physician, be referred to a transplant center, or be approached by the transplant center once referred.

Pancreas Two retrospective analyses of national data have described inequities in the pancreas transplant selection process

A study using the USRDS data revealed that White patients received $92 \%$ of all simultaneous pancreas-kidney transplants (SPKT) [117]. Lack of private insurance and unemployment status were associated with lower transplant rates. Following initiation of Medicare coverage for SPKT in 1999, Black and Hispanic patients had almost 30\% lower SPKT registration rates than their White counterparts, and the disparity was more substantial for non-White patients with primary Medicare insurance than those with private insurance [118].

\section{Living donor identification and evaluation Abdominal}

Kidney Eleven clinical trials have tested interventions to reduce disparities in living donor kidney transplant (LDKT): six trials focused on educational interventions, three focused on enhanced support for patients identifying living donors, and two focused on changing care delivery for potential living donors. Three studies were ongoing at the time of our query

\section{Educational Interventions:}

The Enhancing Living Donor Kidney Transplant Education (ELITE) Study was a cluster randomized trial assessing the ability of an educational intervention to improve knowledge of LDKT. Five hundred potential transplant candidates were cluster-randomized to receive either: (1) usual standard-of-care transplant education or (2) intensive education based upon the Explore Transplant educational materials [119]. The intensive education resulted in higher knowledge compared with usual care (12.7 vs 11.7 ; $P=.0008)$ and increased willingness to take steps toward LDKT. However, there were no differences in post-evaluation readiness for LDKT [120].

A multisite randomized controlled trial evaluated the efficacy of exposure to a bilingual, culturally-targeted website (titled Infórmate) for increasing Hispanic patients' knowledge about LDKT. Website content (including images, telenovela scripts, and messages) was informed by focus groups composed of adult Hispanic kidney transplant recipients, living kidney donors, dialysis patients, and the Hispanic community [121]. Following implementation, website exposure was associated with a mean increase of $22 \%$ in knowledge of LDKT which was sustained at 3 weeks post-exposure, compared with control scores that increased by $12 \%(P=.0001)$. Website exposure was also associated with a $10 \%$ greater knowledge score at three-week follow-up $(P<.0001)$, and $93 \%$ of patients reported a plan to return to Infórmate in the future [122]. A separate pretest/posttest intervention study was conducted among adult Hispanic patients undergoing dialysis at five dialysis centers and showed website exposure was associated with a mean $17 \%$ sameday knowledge score increase between pretest and posttest $(P<.001)$ that was sustained at 3 weeks. Most participants (95\%) "agreed" or "strongly agreed" that they would recommend the website to other Hispanic patients [123].

A multicenter randomized controlled trial tested the effectiveness of a revised Living ACTS (About Choices in Transplantation and Sharing) intervention to increase knowledge of LDKT and willingness to discuss LDKT with family members. The web-based intervention Living ACTS was developed for Black patients with kidney disease and included five educational modules: Introduction, Benefits and Risks, The Kidney Transplant Process, Identifying a Potential Kidney Donor, and ACT Now (which encourages communication with friends and family about transplantation) [124]. Intervention participants demonstrated a significantly greater increase in knowledge of LDKT and greater willingness to talk to their families about LDKT than did control participants. However, the effect of the intervention was not sustained at six-month follow-up [125]. 
A parallel group, two-arm randomized controlled trial is testing an educational and behavioral intervention designed to increase receipt of LDKT among Black transplant candidates [126]. Candidates on the waitlist are randomly assigned to one of two conditions: (1) a control group that will receive usual care, or (2) an intervention group that will receive Destination Transplant, a ninemonth intervention that includes an in-person groupbased education session, postcards at monthly intervals, and a follow-up phone call from a transplant educator. At baseline and during 18 months of follow-up, demographic, clinical, and other variables are to be collected, such as transplant derailers (factors that might be sources of delay, difficulty, or challenge to pursuing transplant), transplant knowledge, health literacy, small steps taken to pursue LDKT, readiness for LDKT, decisional balance and self-efficacy measures, decisional conflict, family support, availability of potential living donors, and general health status.

Your Path to Transplant is a randomized controlled trial of a computer-based education intervention to increase LDKT. The education intervention consists of individually-tailored telephonic coaching sessions, feedback reports, video- and print-based transplant education resources, and assistance with reducing any known socioeconomic barriers to LDKT [127].

Talking About Live Kidney Donation (TALK) is a twophase mixed-methods study to design and test culturallysensitive interventions to improve patients' consideration of LDKT. Phase 1 involved the development of written and audiovisual educational materials and an accompanying social worker intervention to encourage patients' engagement in consideration of LDKT [128]. Phase 2 is a randomized controlled trial where patients with CKD are assigned to receive: (1) usual care by their nephrologists, (2) usual care plus the educational materials, or (3) usual care plus the educational materials and social worker intervention. The primary outcome is self-reported rates of consideration of LDKT, including family and patientphysician discussions and identification of a living kidney transplant donor.

\section{Enhanced support for patients identifying living donors}

House Calls is an intervention to directly engage the social network of CKD patients in LDKT education. The intervention consisted of a single 60 to 90 -min session delivered to the patient and their social network by health educators in the patient's home. The randomized trial had three intervention arms in which health educators delivered an intervention to: (1) the patient and his/her guests in the patient's home (House Calls arm [HC]), (2) clusters of patients and their guests in the transplant center (GroupBased arm [GB]), or (3) the individual patient alone in the transplant center (Individual Counseling arm [IC]). At the two-year endpoint, $\mathrm{HC}$ patients were more likely than GB and IC patients to have at least one donor inquiry ( $82 \%$ vs $61 \%$ vs $47 \%$; $P=.001)$ and evaluation $(65 \%$ vs $39 \%$ vs $27 \%$; $P<.001)$. HC patients also were more likely than other patients to have higher knowledge, fewer concerns, and higher willingness to talk to others about donation 6 weeks post-intervention [129]. A subsequent secondary analysis of data collected as part of the House Calls trial assessed LDKT readiness stage, knowledge, concerns, and willingness to talk to others about living donation at 2 years post-intervention. $60 \%$ of patients were not considering or not yet ready to pursue LDKT, while only $11 \%$ had taken action to talk to family members or friends about the possibility of living kidney donation. Patients in later stages of LDKT readiness (i.e., had talked to others about donation or were preparing to do so) had significantly more knowledge $(P<.001)$, fewer concerns $(P=.002)$, and more willingness $(P=.001)$ to talk to others about living donation than those in earlier readiness stages [130].

The Providing Resources to Enhance African American Patients' Readiness to Make Decisions about Kidney Disease (PREPARED) Study was a six-month randomized controlled trial of Black patients with ESRD who had recently initiated in-center hemodialysis. Participants were randomly assigned to receive: (1) usual dialysis care in the dialysis facility, (2) informational decision aids (i.e., a video and a book describing LDKT and other forms of renal replacement therapy, referred to as "PREPARED information"), or (3) the PREPARED information plus a living kidney donor financial assistance program [131]. In total, $62 \%$ of participants reported that interventions helped their decision-making about renal replacement treatments, but there were no statistically significant improvements in LDKT actions among groups at 6 months and no participants utilized the living donor financial assistance benefit [132].

The Talking about Living Kidney Donation Support (TALKS) study in an ongoing trial designed to evaluate the effectiveness of three interventions by conducting a randomized controlled trial in which patients on the deceased donor waitlist receive: (1) usual care while on the transplant waitlist, (2) an educational and social worker intervention, or (3) an educational and social worker intervention plus the option of participating in a financial assistance program. The primary outcome of the study measures potential recipients' live kidney donor activation (a composite rate of live donor inquiries, newly 
completed live donor evaluations, or live kidney donation) at 1 year [133].

\section{Changing care delivery for potential living donors}

An ongoing, two-part study to evaluate the effectiveness of a streamlined single-day evaluation process (dubbed KTFT-TALK) is comprised of (1) Kidney Transplant Fast Track (KTFT) aimed at increasing transplant rates), and (2) the Talking About Live Kidney Donation (TALK) educational intervention aimed at increasing LDKT. The KTFT approach involves completing most or all testing on the same day when candidates arrive for their first pretransplant clinic appointment. Patients were randomly assigned to the TALK intervention after initial study recruitment [134]. Another ongoing trial based on the TALK interventions uses an effectiveness-implementation hybrid design involving pre-post intervention evaluation with matched controls to implement a complex culturally-targeted intervention at two transplant centers in Dallas, Texas and Phoenix, Arizona. The goal of the TALK component here is to evaluate the effect of Northwestern Medicine's ${ }^{\circledR}$ Hispanic Kidney Transplant Program's (HKTP) key culturally-targeted components (outreach, communication, education) on Hispanic LDKT rates over 5 years [135].

\section{Eleven retrospective studies of national databases described inequities in LDKT}

These studies have demonstrated lower rates of LDKT among racial/ethnic minority patients [136-140], including preemptive transplant from living donors [141], women [137, 142], and patients with low education and SES level $[137,140,143,144]$. At the transplant-center level, increased racial disparity has been associated with higher percentages of Black candidates, preemptively listed candidates and low rates of LDKT [145]. Nondirected living donation specifically has been shown to cluster at certain US-based centers with a consistently low rate of receipt by Black patients [146].

\section{Six regional and single-center retrospective studies investigated disparities in LDKT}

The findings echoed those of larger studies, that neither interest in nor pursuit of LDKT were associated with knowledge, health literacy, or medical mistrust [147]. More Black patients than others initiated dialysis without prior care for CKD; these patients experienced longer time to transplant in the absence of nephrology care [148]. Ineligible recipients were also more commonly Black patients [149-152].

\section{Two studies reported clinician perceptions of inequi- ties in LDKT}

Although we found no surveys of clinician opinions about disparities in LDKT, the Live Donor Community of Practice within the American Society of Transplantation held a Consensus Conference on Best Practices in Live Kidney Donation in June 2014. Following the conference, the committee suggested several system-level interventions to improve equity in LDKT. These included removal of financial disincentives to kidney donation, implementation for education programming that is culturally-tailored and community-based, use of transplant liaisons between transplant centers and community nephrology care, and additional research to improve understanding LDKT disparities and LKD differences [153, 154].

A survey of ApoL1 genetic testing practices for living kidney donors was disseminated via email to nephrologists and transplant surgeons at 63 transplant centers in the US that currently have had at least 10 Black living donors per year according to the 2015 UNOS data [155]. A high degree of variability in ApoL1 testing practices was found across transplant centers, potentially reflecting the continued clinical uncertainty of the role that ApoL1 testing has in most potential at-risk donors. The approach taken by most transplant centers consisted of a donor candidate's self-report of race. Less than $20 \%$ of surveyed clinicians expressed concern about ApoL1 testing stigmatizing minorities.

\section{Eleven studies reported patient perspectives about inequities in LDKT}

Lack of knowledge and misinformation are commonly reported barriers to LDKT among racial and ethnic minority patients. Although patients with ESRD report being willing to accept a kidney from a living donor, they also admit discomfort with asking someone to donate [156]. Donors report having encountered negative responses from others about their desire to donate and also refusal of recipients to accept an LDKT offer [157]. Black donors also reported concerns related to experiences of racial discrimination by healthcare clinicians [158]. Various types of social support have helped donors and recipients navigate the transplant process, including coping strategies. Recipients identified faith as a coping mechanism, while donors identified normalization of donation as their method of coping [104]. Attitudes toward dialysis are moderated by both trust in LDKT and 
trust in racial equity as related to LDKT [159]. Decisional balance and self-efficacy are important mediators of trust and discomfort among all races and education levels [160].

Women report less interest in receiving LDKT than men, despite being nearly twice as likely as men to receive unsolicited offers for kidney transplant. Women are also less likely than men to have been evaluated for a kidney transplant [161]. However, women make more living donor requests than men, irrespective of race. The barrier to a living donor transplant for most women was not the size of their social support network or lack of requesting a living donor, but rather undefined factors related to the network members themselves [162].

Costs of care and concern for financial strain are commonly reported barriers for donors and recipients. Outof-pocket expenses were greater for transplant recipients than donors, even though worries about future medical costs were common in both groups [98]. Racial and ethnic minorities in particular expressed unique concerns related to socioeconomic stresses and ways of coping with the stress of donation [158]. Non-English-speaking recipients reported concerns about disqualification of prospective family member donors due to medical issues, inability to miss work, undocumented residency status, inability to support their family if they donate, and declining social support because of illness [163]. This may influence participation in evaluation processes, where consistent attendance has been associated with concerns about finding a living donor $(P=.038)$ and higher perceived general knowledge about transplantation $(P<.001)[97]$.

\section{Liver Three studies investigated disparities in access to living donor liver transplant (LDLT)}

National registry data shows that $\mathrm{racial} / \mathrm{ethnic}$ minorities receive a disproportionately low percentage of LDLTs, and this is thought to be in part due to fewer initial inquiries by potential donors [164]. LDLT is also less likely for recipients who are older, single, divorced, immigrants, and from the lowest income quintile [165]. When surveyed, patients reported preferring to donate and die while the transplant recipient lives, rather than forgo donation and have the potential transplant recipient die of liver failure. Participants' stated threshold for living donation was a median survival for themselves as donor of $79 \%$, along with a median survival of $55 \%$ for recipients with transplantation, before they would agree to donate. Race was the most statistically significant predictor of those thresholds. $81 \%$ of respondents believed that the potential donor, not a physician, should have the final say regarding candidacy for living donation [166].

\section{Waitlist outcomes (including organ selection/utilization) Thoracic}

\section{Heart Eight studies investigated disparities in wait- list outcomes among heart transplant candidates}

Black and Hispanic patients were more likely to be listed with higher urgency (listing status 1A/1B) compared with White patients, and Hispanic patients were at higher risk of waitlist mortality [167]. Black race was found to be significantly associated with longer time to cardiac transplantation [168], lower likelihood of receiving a heart transplant, and greater likelihood of being removed from the waitlist due to worsening health $[169,170]$. Women receiving LVAD support also had a reduced chance of heart transplantation and increased risk of waitlist mortality and delisting for worsening clinical status within 2 years post-implantation [171]. Low median household income was associated with an increased risk of readmission and time to first event after LVAD implantation [172], and waitlist mortality was found to be greater among Medicaid beneficiaries [173]. The single study that investigated transplantation as a primary outcome demonstrated no difference by insurance status [174].

\section{Abdominal}

Kidney One prospective study described disparities in waitlist outcomes among kidney transplant candidates

Older age, higher number of comorbidities, transplantation before changes to the KAS, greater religiosity, less social support, and fewer learning activities were each associated with a decreased probability of deceaseddonor kidney transplant [175]. Black race, older age, lower income, public insurance status, higher body mass index, dialysis before kidney transplant, not presenting with a potential living donor, religious objection to livingdonor transplant, and less transplant knowledge were each associated with a decreased probability of livingdonor transplant.

Twenty retrospective studies of national databases have described disparities in waitlist outcomes among kidney transplant candidates 
National waitlist and transplant rates were comparatively low among minority populations, particularly in high-ESRD incidence donor service areas [176]. Poverty rate, Black race, education, and unemployment in the surrounding community are all significant modifiers of center-level transplant rates [177, 178]. Simulations showed that 30 to 65 waitlist spots or transplant operations per 1000 patients would shift from economically advantaged to disadvantaged persons if socioeconomics no longer influenced organ allocation decisions [179].

Preemptive deceased donor kidney transplant occurs most frequently in patients with private insurance, previous (non-kidney) transplant, and zero-antigen mismatch [180-182]. Implementation of KAS led to an increase in Black and Hispanic patients on the kidney transplant waitlist [183] and an increase in preemptively transplanted minorities [184-186]. However, large differences in the adjusted probability of deceased donor kidney transplantation persisted under KAS, with probability of transplantation significantly associated with organ offer acceptance patterns at transplant centers [187].

Among waitlisted patients, racial and ethnic minorities were more likely to be hospitalized while waitlisted, decreasing the likelihood of being transplanted [188]. Once on the inactive list, White patients were more likely than Hispanic patients to resolve issues for inactivity, resulting in reactivation [189]. Nationally, deceased donor transplantation occurred at a lower rate for Black, Hispanic, Asian/ Pacific Islander, and other minority groups compared to White patients [190]. Older patients and Black and Asian recipients also received lower-quality organs relative to young non-Hispanic White patients [191].

Studies examining USRDS data largely echoed the same findings. Adjusted rates of deceased donor kidney transplantation were significantly lower among racial/ethnic minority groups compared to White patients. Differences in time to waitlisting were not as pronounced as differences in time between waitlisting and transplantation. Determinants of delays in time to transplantation differed substantially by racial/ethnic group [192, 193]. A decreased likelihood of deceased donor transplantation was also associated with long travel distances to the transplant center [194]. VA-insured and Medicare/Medicaidinsured patients were less likely to be placed on the waitlist and less likely to receive transplants than patients with private insurance. VA patients with supplemental private insurance had the same likelihood of transplantation as non-VA patients with private insurance [195].
Three studies reported patient perspectives on barriers to kidney transplant among waitlisted patients

Most caregivers reported either little-to-none or mild-tomoderate burden, which was greatest among the caregivers of patients who received assistance from someone else (a third party) for activities of daily living (ADLs) [196]. Factors associated with patient-reported likelihood of being waitlisted included Medicare and Medicaid insurance, Black race, community deprivation, and non-US citizen status [197]. Race-related differences in SES, health and functional status, severity of illness, biological factors, existence of contraindications to transplantation, transplant center characteristics, and patients' attitudes about dialysis and transplantation were predictive factors [198].

\section{Liver Two single-center prospective cohort examined disparities in waitlist outcomes among patients listed for liver transplant}

Women on the waitlist for liver transplant were significantly more likely to have non liver-related comorbidities, pain medication usage, and infectious complications. Women also had an increased risk of hospitalization, an increase in number of inpatient days within 12 months of listing and a greater risk of dying in the hospital [199, 200].

\section{Twenty-five retrospective studies of national data- bases and three of single-center data described dis- parities in waitlist outcomes among patients listed for liver transplant}

Studies using the UNOS database demonstrated an association between social determinants of health and severity of illness at listing. Education, employment, and private insurance were associated with being changed to a lower priority status and patients with Medicaid as their primary payer had a decreased likelihood of receiving a symptom-based exception [201]. Race, Hispanic ethnicity, insurance status, and lower education predicted delisting [202, 203]. Black race, Hispanic ethnicity, female gender, public insurance, and geographic isolation were associated with increased waitlist mortality and decreased likelihood of receiving a liver transplant [204223]. The three single-center retrospective studies reinforced the national findings, that male gender is highly correlated with the likelihood of getting a transplant [220], public insurance is associated with increased risk of waitlist mortality, compared with private insurance [224] and the ability to improve waitlist outcomes by pursuing transplant at a second center is also concentrated among candidates with private insurance [225]. 


\section{One study reported patient perspectives on barriers to transplant among waitlisted patients}

Appalachian residence was associated with lower access to transplantation after listing for liver transplant. This geographic disparity should be addressed in the current debate over reforming donor liver allocation and patient priority for liver transplant [226].

\section{Discussion}

The most simplistic way to look at disparities in transplant is as a matter of scarcity, i.e., a limited number of deceased donor organs to a patient population with large demand. In order to address this, Congress issued the Final Rule which was enacted in 2000 as a way to have a uniform distribution policy of organs across the transplant waitlist.

When we shift, however, from a goal of equality - all patients on the list having similar access to transplantable organs, to equity-all patients receive the support they need to successfully undergo transplantation- the problem becomes much more complex. Health equity in transplantation is an elusive goal, with multi-level barriers and facilitators along the care continuum. Delayed diagnosis/referral of patients with end-stage organ disease and the complexity of the evaluation processincluding requisite contact with several clinicians and nuanced multidimensional risk assessment-- all contribute to difficulties accessing the transplant waitlist. Disparities in access to transplant and drivers of inequitable access have been described for more than 30 years. However, it is unclear what actionable knowledge or progress towards equity in access to transplant has been gained since that time.

Sweeping changes which alter organ allocation to listed patients such as the introduction of the KAS system for kidney allocation or the MELD score have made an impact toward equity on patients listed for kidneys and livers. However, these changes have not simplified the process of gaining access to the waitlist. The complexity of the process and resources required to participate in it are exacerbated for patients who pursue transplant from a living donor.

We conducted a scoping review of the literature to identify studies describing disparities and health inequities in transplant. Our goal was to identify the types of evidence available in this area and to identify gaps in the knowledge of which disparities are inequities. We hypothesized that most research describing disparities and health inequities in transplant is (1) focused on patients after addition to the organ transplant waitlist, and (2) focused on kidney transplant. We also hypothesized that most research aimed at understanding the influence of social determinants of health on access to transplant is limited to race, gender and insurance status. Our review identified 227 publications. Of these, 34 focused on referral of patients with chronic organ disease, 82 focused on the transplant selection process, and 111 focused on patients after addition to the organ transplant waitlist. Only 15 studies involved thoracic transplant, and of the 209 focused on abdominal transplant, 166 focused on kidney transplant. In total there were only 13 clinical trials and 11 prospective studies.

The results of this review bring to light several overarching themes, which appear to be consistent across all organs. Race and gender are the most commonly studied social determinants of health and have a significant impact on their own, as well as powerful interactions with other social determinants of health, in influencing access to transplantation. Other social determinants of health, such as education, insurance status, geographic isolation from a transplant center, and family support, are all strongly associated with disparities. However, evidence gaps remain as to the direct causal pathways between social determinants of health and risk of adverse outcomes.

Patient level barriers are a significant component of inequitable access: knowledge, trust, and communication with caregivers and medical providers are consistently identified determinants of access to transplant-even so much as to help overcome other patientlevel barriers, such as income. Serious persistent misinformation and lack of awareness of the benefits of transplant continue to be identified when patients from disenfranchised populations are directly surveyed. Multicomponent interventions have focused on activation of patient behavior based on increased information and the overall results show that well-designed educational interventions will motivate initial but not sustained action, resulting in improved initiation of process but not durable reduction in waitlist disparities.

The role of the primary specialist is critical. In particular, direct survey of clinicians reveals interpersonal bias and both racism and sexism in clinical encounters have been cited by investigators and patients. Some of this may be clinician bias related to engagement with the health system and making optimal use of donated organs. Unfortunately, very little work has examined transplant clinician bias and more research is needed in this area. Recent Center for Medicare and Medicaid changes in how dialysis centers are now getting judged on transplant listing vs referral.

When information from all organs is considered, large gaps remain in the evidence connecting social 
determinants of health to timely referral, successful evaluation and listing for transplant. Reviewing the literature in detail identified several concerns:

1. The overwhelming majority of health equity research in transplantation has been done in kidney transplant, with far fewer studies in liver or thoracic transplant and only two studies focused on pancreas transplant. This is likely due to the existence of USRDS, which allows for tracking of the management of patients with ESRD from initiation of dialysis through death and/or transplantation, but no similar registry exists for patients with liver disease. Progress towards equity in access to liver transplant will remain hindered by lack of epidemiologic data. In addition, no national data source currently exists that reliably distinguishes patient progress through the transplant selection process.

2. Limited work on referral has demonstrated that although interventions aimed at increasing patient knowledge are generally effective, they are insufficient to achieve health equity in referral rates. Clinician bias as well as lack of education about disparities continue to play a prominent role.

3. Large disparities in the ability to complete the evaluation process affect women, racial/ethnic minority patients, the geographically isolated, and patients who are uninsured or covered by public insurance. This area of the transplantation process remains vague, with only two clinical trials conducted to date and no evidence that interventions have a significant effect on waitlisting rates.

4. Access to living donors represents an unattainable goal for many. Living donor liver transplant is a highly specialized aspect of care and varies significantly from center to center. The adult-to-adult living donor liver transplant consortium investigated safety in living donation, but no group has examined equity. In kidney transplantation, the disparity in the ability of racial/ethnic minority patients to undergo LDKT appears to be in part, but not completely, due to lack of knowledge about the benefits of living donor transplant and particularly preemptive transplant. Educational interventions and culturally-competent and tailored engagement with the transplant center has shown great promise, with several clinical trials still underway.

5. Even among patients who successfully gain access to the transplant waitlist, disparities continue to negatively affect access to high-quality organs. Removal from the waitlist, waitlist mortality, and quality of organ selection all remain inequitable. Though beyond the scope of our review, our search identified more than 200 publications reporting disparities in post-transplant outcomes. This area deserves continued investigation.

6. Social determinants of health are frequently limited to race, gender and insurance status. These variables are collected in national registries, but fail to fully capture the influence of social risk on overall success as a transplant candidate. There is chronic under-utilization of more enhanced social determinants of health, such as food insecurity, educational access and built environment. Despite numerous studies describing observed differences in access to and outcomes after transplant, no work has reliably established causal mechanisms for these differences. Without this, efforts to eliminate these differences will likely continue to have limited success, underscoring the need for improved data collection in this area.

Several limitations warrant mention. First, our review only included studies published in the US and therefore may have omitted relevant studies of social determinants of health and access to transplantation. Similarly, we did not include studies in languages other than English due to lack of resources. Finally, we did not conduct risk of bias assessment of included studies or meta-analysis of findings as the purpose of this scoping review was to collate a wide range of studies of disparities and inequities in access to transplant of all organ types in order to assess the scope of the evidence base to date and identify gaps in evidence.

\section{Conclusion}

In summary, there is a need for improved research in health equity in transplantation. Although the clinical presentation and subspecialty evaluation differ between various subsets of patients with end-stage organ disease, the process of prompt diagnosis, access to subspecialty care, and efficient referral is universal. Equity in access to organ transplantation requires the ability of patients to benefit from early diagnosis of end-stage organ disease and receipt of prompt referral for transplant evaluation. Although patient interest in transplantation plays a role, other potential drivers include patients' preferences, knowledge of transplantation, challenges navigating the referral and selection processes, communication and trust between patients and clinicians, and structural and personal bias. Very little work has been done to identify and mitigate disparities at this stage in the process and should be the focus of future research to elucidate potential approaches for intervention. Ultimately, an equitable system would allow all patients who have an end organ condition that can be helped by transplant the same access to transplant. In addition to this, the change would ideally be "effortless" to patients so that people, who are 
already burdened with disease, do not have to make any additional effort to recognize the benefit of this change.

\begin{abstract}
Abbreviations
ACTS: About Choices in Transplantation and Sharing; ADL: Activities of daily living; ASCENT: Allocation System Changes for Equity in Kidney Transplantation; CKD-EPI: Chronic Kidney Disease Epidemiology Collaboration; eGFR: Estimated glomerular filtration rate; ELITE: Enhancing Living Donor Kidney Transplant Education; ESRD: End-stage renal disease; GFR: Glomerular filtration rate; HKTP: Hispanic Kidney Transplant Program; KAS: Kidney allocation system; KTFT: Kidney Transplant Fast Track; LDKT: Living donor kidney transplant; LDLT: Living donor liver transplant; LVAD: Left ventricular assist device; MELD: Model for End-Stage Liver Disease; PREPARED: Providing Resources to Enhance African American Patients' Readiness to Make Decisions about Kidney Disease; RaDIANT: Reducing Disparities in Access to kidNey Transplantation; SAl: Social Adaptability Index; SES: Socioeconomic status; SPKT: Simultaneous pancreaskidney transplants; SRTR: Scientific Registry of Transplant Recipients; TALK: Talking About Live Kidney Donation; TALKS: Talking about Living Kidney Donation Support; UNOS: United Network for Organ Sharing; US: United States; USRDS: United States Renal Data System;VA: Veterans Administration.
\end{abstract}

\section{Supplementary Information}

The online version contains supplementary material available at https://doi. org/10.1186/s12939-021-01616-x.

Additional file 1. Search strategy report for socioeconomic disparities and organ transplantation in queried databases.

\section{Acknowledgements}

Not applicable.

\section{Authors' contributions}

Study concept and design: MJ, SK, FK, LM, JW, EB. Literature screening and review: MJ, SK, FK, LM, CP, JW. Manuscript preparation: LM, CP. Manuscript review: CP, MJ, LM, FK. The author(s) read and approved the final manuscript.

\section{Funding}

Research reported in this publication was supported by the National Institute on Minority Health and Health Disparities under Award Number U54MD012530. The content is solely the responsibility of the authors and does not necessarily represent the official views of the National Institutes of Health.

\section{Availability of data and materials}

Not applicable.

\section{Declarations}

Ethics approval and consent to participate

Not applicable.

\section{Consent for publication}

Not applicable.

\section{Competing interests}

Not applicable.

\section{Author details}

${ }^{1}$ Division of Abdominal Transplant, Department of Surgery, Duke University School of Medicine, Durham, NC, USA. ${ }^{2}$ Division of Cardiac Anesthesiology, Department of Anesthesiology, Weil Cornell Medicine, New York, NY, USA. ${ }^{3}$ Medical Center Library and Archives, Duke University School of Medicine, Durham, NC, USA. ${ }^{4}$ Division of Abdominal Transplant, Department of Surgery, University of Mississippi School of Medicine, Jackson, MS, USA. ${ }^{5}$ Division of Gastroenterology, Department of Medicine, Duke University School of Medicine, Durham, NC, USA. ${ }^{6}$ Division of General Internal Medicine, Department of Medicine, Duke University School of Medicine, Durham, NC, USA.

Received: 29 August 2021 Accepted: 24 December 2021

Published online: 12 February 2022

\section{References}

1. OPTN/SRTR 2018 annual data report: introduction. Am JTransplant 2020:20 Suppl s1:11-19. https://doi.org/10.1111/ajt.15671.

2. Munn Z, Peters MDJ, Stern C, Tufanaru C, MCArthur A, Aromataris E. Systematic review or scoping review? Guidance for authors when choosing between a systematic or scoping review approach. BMC Med Res Methodol. 2018;18(1):143.

3. Thakkar S, Majmundar M, Kumar A, Kansara T, Adalja D, llyas I, et al. Comparison of management and outcomes of acute heart failure hospitalization in medicaid beneficiaries versus privately insured individuals. Am J Cardiol. 2020;125(7):1063-8.

4. Breathett $\mathrm{K}$, Yee E, Pool N, Hebdon M, Crist JD, Yee RH, et al. Association of gender and race with allocation of advanced heart failure therapies. JAMA Netw Open. 2020;3(7):e2011044.

5. Patzer RE, Gander J, Sauls L, Amamoo MA, Krisher J, Mulloy LL, et al. The RaDIANT community study protocol: community-based participatory research for reducing disparities in access to kidney transplantation. BMC Nephrol. 2014;15:171.

6. Hamoda RE, Gander JC, McPherson LJ, Arriola KJ, Cobb L, Pastan SO, et al. Process evaluation of the RaDIANT community study: a dialysis facility-level intervention to increase referral for kidney transplantation. BMC Nephrol. 2018;19(1):13.

7. Patzer RE, Paul S, Plantinga L, Gander J, Sauls L, Krisher J, et al. A randomized trial to reduce disparities in referral for transplant evaluation. J Am Soc Nephrol. 2017;28(3):935-42.

8. Waterman AD, MCSorley AM, Peipert JD, Goalby CJ, Peace LJ, Lutz PA, et al. Explore transplant at home: a randomized control trial of an educational intervention to increase transplant knowledge for Black and White socioeconomically disadvantaged dialysis patients. BMC Nephrol. 2015;16:150.

9. Waterman AD, Peipert JD. An explore transplant group randomized controlled education trial to increase dialysis patients' decision-making and pursuit of transplantation. Prog Transplant. 2018;28(2):174-83.

10. Waterman AD, Peipert JD, McSorley AM, Goalby CJ, Beaumont JL, Peace L. Direct delivery of kidney transplant education to black and lowincome patients receiving dialysis: a randomized controlled trial. Am J Kidney Dis. 2019;74(5):640-9.

11. Zelnick LR, Leca N, Young B, Bansal N. Association of the estimated glomerular filtration rate with vs without a coefficient for race with time to eligibility for kidney transplant. JAMA Netw Open. 2021;4(1):e2034004.

12. Kucirka LM, Grams ME, Balhara KS, Jaar BG, Segev DL. Disparities in provision of transplant information affect access to kidney transplantation. Am J Transplant. 2012;12(2):351-7.

13. Ku E, Lee BK, McCulloch CE, Roll GR, Grimes B, Adey D, et al. Racial and ethnic disparities in kidney transplant access within a theoretical context of medical eligibility. Transplantation. 2020;104(7):1437-44.

14. Wong LL, Kindle K, Limm B. Racial disparities in pacific islanders undergoing renal transplant evaluation. Hawaii Med J. 2009;68(2):30-3.

15. Soucie JM, Neylan JF, McClellan W. Race and sex differences in the identification of candidates for renal transplantation. Am J Kidney Dis. 1992;19(5):414-9.

16. Patzer RE, McPherson L, Wang Z, Plantinga LC, Paul S, Ellis M, et al. Dialysis facility referral and start of evaluation for kidney transplantation among patients treated with dialysis in the southeastern United States. Am J Transplant. 2020;20(8):2113-25.

17. McPherson LJ, Barry V, Yackley J, Gander JC, Pastan SO, Plantinga LC, et al. Distance to kidney transplant center and access to early steps in the kidney transplantation process in the southeastern United States. Clin J Am Soc Nephrol. 2020;15(4):539-49.

18. Ahmed S, Nutt CT, Eneanya ND, Reese PP, Sivashanker K, Morse M, et al. Examining the potential impact of race multiplier utilization in estimated glomerular filtration rate calculation on African-American care outcomes. J Gen Intern Med. 2021;36(2):464-71. 
19. Lipford KJ, McPherson L, Hamoda R, Browne T, Gander JC, Pastan SO, et al. Dialysis facility staff perceptions of racial, gender, and age disparities in access to renal transplantation. BMC Nephrol. 2018;19(1):5.

20. Kim JJ, Basu M, Plantinga L, Pastan SO, Mohan S, Smith K, et al. Awareness of racial disparities in kidney transplantation among health care providers in dialysis facilities. Clin J Am Soc Nephrol. 2018;13(5):772-81.

21. Ayanian JZ, Cleary PD, Keogh JH, Noonan SJ, David-Kasdan JA, Epstein AM. Physicians' beliefs about racial differences in referral for renal transplantation. Am J Kidney Dis. 2004;43(2):350-7.

22. Balhara KS, Kucirka LM, Jaar BG, Segev DL. Disparities in provision of transplant education by profit status of the dialysis center. Am J Transplant. 2012;12(11):3104-10.

23. McCauley J, Irish W, Thompson L, Stevenson J, Lockett R, Bussard R, et al. Factors determining the rate of referral, transplantation, and survival on dialysis in women with ESRD. Am J Kidney Dis. 1997;30(6):739-48.

24. Waterman AD, Peipert JD, Xiao H, Goalby CJ, Kawakita S, Cui Y, et al. Education strategies in dialysis centers associated with increased transplant wait-listing rates. Transplantation. 2020;104(2):335-42.

25. Ayanian JZ, Cleary PD, Weissman JS, Epstein AM. The effect of patients' preferences on racial differences in access to renal transplantation. $\mathrm{N}$ Engl J Med. 1999;341(22):1661.

26. Jones D, You Z, Kendrick JB. Racial/ethnic differences in barriers to kidney transplant evaluation among hemodialysis patients. Am J Nephrol. 2018;47(1):1-7.

27. Knight RJ, Teeter LD, Graviss EA, Patel SJ, DeVos JM, Moore LW, et al. Barriers to preemptive renal transplantation: a single center questionnaire study. Transplantation. 2015;99(3):576-9.

28. Salter ML, Kumar K, Law AH, Gupta N, Marks K, Balhara K, et al. Perceptions about hemodialysis and transplantation among African American adults with end-stage renal disease: inferences from focus groups. BMC Nephrol. 2015;16:49.

29. Hamoda RE, McPherson LJ, Lipford K, Jacob Arriola K, Plantinga $L$, Gander JC, et al. Association of sociocultural factors with initiation of the kidney transplant evaluation process. Am J Transplant. 2020;20(1):190-203.

30. Waterman AD, Lipsey AF, Ranasinghe ON, Wood EH, Anderson C, Bozzolo C, et al. Recommendations for systematizing transplant education within a care delivery system for patients with chronic kidney disease stages 3 to 5. Prog Transplant. 2020;30(2):76-87.

31. Browne T. The relationship between social networks and pathways to kidney transplant parity: evidence from black Americans in Chicago. Soc Sci Med. 2011;73(5):663-7.

32. Ilori TO, Enofe N, Oommen A, Odewole O, Ojo A, Plantinga L, et al. Factors affecting willingness to receive a kidney transplant among minority patients at an urban safety-net hospital: a cross-sectional survey. BMC Nephrol. 2015;16:191.

33. Salter ML, McAdams-Demarco MA, Law A, Kamil RJ, Meoni LA, Jaar BG, et al. Age and sex disparities in discussions about kidney transplantation in adults undergoing dialysis. J Am Geriatr Soc. 2014;62(5):843-9.

34. Julapalli VR, Kramer JR, El-Serag HB, American Association for the Study of Liver D. Evaluation for liver transplantation: adherence to AASLD referral guidelines in a large veterans affairs center. Liver Transpl. 2005;11(11):1370-8.

35. Bryce CL, Angus DC, Arnold RM, Chang CC, Farrell MH, Manzarbeitia C, et al. Sociodemographic differences in early access to liver transplantation services. Am J Transplant. 2009;9(9):2092-101.

36. Kemmer N, Alsina A, Neff GW. Orthotopic liver transplantation in a multiethnic population: role of spatial accessibility. Transplant Proc. 2011:43(10):3780-2

37. Axelrod DA, Guidinger MK, Finlayson S, Schaubel DE, Goodman DC, Chobanian M, et al. Rates of solid-organ wait-listing, transplantation, and survival among residents of rural and urban areas. JAMA. 2008;299(2):202-7.

38. Miller-Matero LR, Bryce K, Hyde-Nolan ME, Dykhuis KE, Eshelman A, Abouljoud M. Health literacy status affects outcomes for patients referred for transplant. Psychosomatics. 2016;57(5):522-8

39. DuBay DA, MacLennan PA, Reed RD, Shelton BA, Redden DT, Fouad $\mathrm{M}$, et al. Insurance type and solid organ transplantation outcomes: a historical perspective on how medicaid expansion might impact transplantation outcomes. J Am Coll Surg. 2016;223(4):611-20 e4.

40. Aaronson KD, Schwartz JS, Goin JE, Mancini DM. Sex differences in patient acceptance of cardiac transplant candidacy. Circulation. 1995;91(11):2753-61.

41. Breathett K, Yee E, Pool N, Hebdon M, Crist JD, Knapp S, et al. Does race influence decision making for advanced heart failure therapies? J Am Heart Assoc. 2019;8(22):e013592.

42. Steinberg RS, Nayak A, O'Connell C, Burford S, Pekarek A, Chesnut N, et al. Sex differences in eligibility for advanced heart failure therapies. Clin Transpl. 2020;34(5):e13839.

43. Hutcheson SS, Phillips V, Patzer R, Smith A, Vega JD, Morris AA. Impact of insurance type on eligibility for advanced heart failure therapies and survival. Clin Transpl. 2018:32(8):e13328.

44. Breathett K, Allen LA, Helmkamp L, Colborn K, Daugherty SL, Khazanie $P$, et al. The affordable care act medicaid expansion correlated with increased heart transplant listings in African-Americans but not Hispanics or Caucasians. JACC Heart Fail. 2017;5(2):136-47.

45. Basu M, Petgrave-Nelson L, Smith KD, Perryman JP, Clark K, Pastan SO, et al. Transplant center patient navigator and access to transplantation among high-risk population: a randomized, controlled trial. Clin J Am Soc Nephrol. 2018;13(4):620-7.

46. Patzer RE, Basu M, Mohan S, Smith KD, Wolf M, Ladner D, et al. A randomized controlled trial of a mobile clinical decision aid to improve access to kidney transplantation: iChoose kidney. Kidney Int Rep. 2016;1(1):34-42.

47. Patzer RE, McPherson L, Basu M, Mohan S, Wolf M, Chiles M, et al. Effect of the iChoose kidney decision aid in improving knowledge about treatment options among transplant candidates: a randomized controlled trial. Am J Transplant. 2018;18(8):1954-65.

48. Patzer RE, Smith K, Basu M, Gander J, Mohan S, Escoffery C, et al. The ASCENT (allocation system changes for equity in kidney transplantation) study: a randomized effectiveness-implementation study to improve kidney transplant waitlisting and reduce racial disparity. Kidney Int Rep. 2017;2(3):433-41.

49. Alexander GC, Sehgal AR. Barriers to cadaveric renal transplantation among blacks, women, and the poor. JAMA. 1998;280(13):1148-52.

50. Myaskovsky L, Kendall K, Li X, Chang CH, Pleis JR, Croswell E, et al. Unexpected race and ethnicity differences in the US National Veterans Affairs Kidney Transplant Program. Transplantation. 2019;103(12):2701-14.

51. Ng YH, Pankratz VS, Leyva Y, Ford CG, Pleis JR, Kendall K, et al. Does racial disparity in kidney transplant waitlisting persist after accounting for social determinants of health? Transplantation. 2020;104(7):1445-55.

52. Alexander GC, Sehgal AR. Why hemodialysis patients fail to complete the transplantation process. Am J Kidney Dis. 2001;37(2):321-8.

53. Patzer RE, Perryman JP, Pastan S, Amaral S, Gazmararian JA, Klein M, et al. Impact of a patient education program on disparities in kidney transplant evaluation. Clin J Am Soc Nephrol. 2012;7(4):648-55.

54. Garg PP, Diener-West M, Powe NR. Reducing racial disparities in transplant activation: whom should we target? Am J Kidney Dis. 2001;37(5):921-31.

55. Garg PP, Furth SL, Fivush BA, Powe NR. Impact of gender on access to the renal transplant waiting list for pediatric and adult patients. J Am Soc Nephrol. 2000;11(5):958-64.

56. Keith D, Ashby VB, Port FK, Leichtman AB. Insurance type and minority status associated with large disparities in prelisting dialysis among candidates for kidney transplantation. Clin J Am Soc Nephrol. 2008;3(2):463-70.

57. Schold JD, Augustine JJ, Huml AM, O'Toole J, Sedor JR, Poggio ED. Modest rates and wide variation in timely access to repeat kidney transplantation in the United States. Am J Transplant. 2020;20(3):769-78.

58. Wolfe RA, Ashby VB, Milford EL, Bloembergen WE, Agodoa LY, Held PJ, et al. Differences in access to cadaveric renal transplantation in the United States. Am J Kidney Dis. 2000;36(5):1025-33.

59. Hall YN. Understanding racial differences in deceased-donor kidney transplantation: geography, poverty, language, and health insurance coverage. Dial Transplant. 2011;40(9):401-6.

60. Whelan AM, Johansen KL, McCulloch CE, Adelmann D, Niemann CU, Roll GR, et al. Longer distance from dialysis facility to transplant center is associated with lower access to kidney transplantation. Transplant Direct. 2020;6(10):e602. 
61. Saunders MR, Lee H, Alexander GC, Tak HJ, Thistlethwaite JR Jr, Ross LF. Racial disparities in reaching the renal transplant waitlist: is geography as important as race? Clin Transpl. 2015;29(6):531-8.

62. Schaeffner ES, Mehta J, Winkelmayer WC. Educational level as a determinant of access to and outcomes after kidney transplantation in the United States. Am J Kidney Dis. 2008;51(5):811-8.

63. Goldfarb-Rumyantzev AS, Sandhu GS, Baird B, Barenbaum A, Yoon JH, Dimitri $\mathrm{N}$, et al. Effect of education on racial disparities in access to kidney transplantation. Clin Transpl. 2012;26(1):74-81.

64. Sandhu GS, Khattak M, Pavlakis M, Woodward R, Hanto DW, Wasilewski $M A$, et al. Recipient's unemployment restricts access to renal transplantation. Clin Transpl. 2013;27(4):598-606.

65. Schold JD, Mohan S, Huml A, Buccini LD, Sedor JR, Augustine JJ, et al. Failure to advance access to kidney transplantation over two decades in the United States. J Am Soc Nephrol. 2021;32:913.

66. Khattak MW, Sandhu GS, Woodward R, Stoff JS, Goldfarb-Rumyantzev AS. Association of marital status with access to renal transplantation. Am J Transplant. 2010;10(12):2624-31.

67. Ahearn P, Johansen KL, Tan JC, McCulloch CE, Grimes BA, Ku E. Sex disparity in deceased-donor kidney transplant access by cause of kidney disease. Clin J Am Soc Nephrol. 2021;16(2):241-50.

68. Goldfarb-Rumyantzev AS, Sandhu GS, Baird BC, Khattak M, Barenbaum A, Hanto DW. Social adaptability index predicts access to kidney transplantation. Clin Transpl. 2011;25(6):834-42.

69. Winkelmayer WC, Mehta J, Chandraker A, Owen WF Jr, Avorn J. Predialysis nephrologist care and access to kidney transplantation in the United States. Am J Transplant. 2007;7(4):872-9.

70. Kurella-Tamura M, Goldstein BA, Hall YN, Mitani AA, Winkelmayer WC. State medicaid coverage, ESRD incidence, and access to care. J Am Soc Nephrol. 2014;25(6):1321-9.

71. Eggers PW. Racial differences in access to kidney transplantation. Health Care Financ Rev. 1995;17(2):89-103.

72. Patzer RE, Amaral S, Wasse H, Volkova N, Kleinbaum D, McClellan WM. Neighborhood poverty and racial disparities in kidney transplant waitlisting. J Am Soc Nephrol. 2009;20(6):1333-40.

73. Segev DL, Kucirka LM, Oberai PC, Parekh RS, Boulware LE, Powe NR, et al. Age and comorbidities are effect modifiers of gender disparities in renal transplantation. J Am Soc Nephrol. 2009;20(3):621-8.

74. Zhang X, Melanson TA, Plantinga LC, Basu M, Pastan SO, Mohan S, et al. Racial/ethnic disparities in waitlisting for deceased donor kidney transplantation 1 year after implementation of the new national kidney allocation system. Am J Transplant. 2018;18(8):1936-46.

75. Gaylin DS, Held PJ, Port FK, Hunsicker LG, Wolfe RA, Kahan BD, et al. The impact of comorbid and sociodemographic factors on access to renal transplantation. Jama. 1993;269(5):603-8.

76. Bloembergen WE, Mauger EA, Wolfe RA, Port FK. Association of gender and access to cadaveric renal transplantation. Am J Kidney Dis. 1997;30(6):733-8.

77. Thamer M, Henderson SC, Ray NF, Rinehart CS, Greer JW, Danovitch GM Unequal access to cadaveric kidney transplantation in California based on insurance status. Health Serv Res. 1999;34(4):879-900.

78. Sequist TD, Narva AS, Stiles SK, Karp SK, Cass A, Ayanian JZ. Access to renal transplantation among American Indians and Hispanics. Am J Kidney Dis. 2004;44(2):344-52.

79. Grubbs V, Gregorich SE, Perez-Stable EJ, Hsu CY. Health literacy and access to kidney transplantation. Clin J Am Soc Nephrol. 2009;4(1):195-200.

80. Abdel-Kader K, Dew MA, Bhatnagar M, Argyropoulos C, Karpov I, Switzer G, et al. Numeracy skills in CKD: correlates and outcomes. Clin J Am Soc Nephrol. 2010;5(9):1566-73.

81. Schold JD, Gregg JA, Harman JS, Hall AG, Patton PR, Meier-Kriesche HU. Barriers to evaluation and wait listing for kidney transplantation. Clin J Am Soc Nephrol. 2011;6(7):1760-7.

82. Patzer RE, Perryman JP, Schrager JD, Pastan S, Amaral S, Gazmararian JA, et al. The role of race and poverty on steps to kidney transplantation in the southeastern United States. Am J Transplant. 2012;12(2):358-68

83. Ahsanuddin S, Bento S, Swerdlow N, Cervera I, Kayler LK. Candidate comprehension of key concepts in kidney transplantation. Ann Transplant. 2015;20:124-31.

84. Monson RS, Kemerley P, Walczak D, Benedetti E, Oberholzer J, Danielson KK. Disparities in completion rates of the medical prerenal transplant evaluation by race or ethnicity and gender. Transplantation. 2015;99(1):236-42.

85. Freeman MA, Pleis JR, Bornemann KR, Croswell E, Dew MA, Chang $\mathrm{CCH}$, et al. Has the department of veterans affairs found a way to avoid racial disparities in the evaluation process for kidney transplantation? Transplantation. 2017;101(6):1191-9.

86. Peng RB, Lee H, Ke ZT, Saunders MR. Racial disparities in kidney transplant waitlist appearance in Chicago: is it race or place? Clin Transpl. 2018;32(5):e13195.

87. $\mathrm{Ng} \mathrm{YH}$, Al Mawed S, Pankratz VS, Argyropoulos C, Singh P, Shaffi SK, et al. Cognitive assessment in a predominantly hispanic and native American population in New Mexico and its association with kidney transplant wait-listing. Clin Transpl. 2019;33(10):e13674.

88. Murphy KA, Jackson JW, Purnell TS, Shaffer AA, Haugen CE, Chu NM, et al. Association of socioeconomic status and comorbidities with racial disparities during kidney transplant evaluation. Clin J Am Soc Nephrol. 2020;15(6):843-51.

89. Epstein AM, Ayanian JZ, Keogh JH, Noonan SJ, Armistead N, Cleary $\mathrm{PD}$, et al. Racial disparities in access to renal transplantation--clinically appropriate or due to underuse or overuse? N Engl J Med. 2000;343(21):1537-44 2 p preceding

90. Garg PP, Diener-West M, Powe NR. Income-based disparities in outcomes for patients with chronic kidney disease. Semin Nephrol. 2001:21(4):377-85.

91. Warsame F, Haugen CE, Ying H, Garonzik-Wang JM, Desai NM, Hall RK, et al. Limited health literacy and adverse outcomes among kidney transplant candidates. Am J Transplant. 2019;19(2):457-65.

92. Clark CR, Hicks LS, Keogh JH, Epstein AM, Ayanian JZ. Promoting access to renal transplantation: the role of social support networks in completing pre-transplant evaluations. J Gen Intern Med. 2008;23(8):1187-93.

93. Spigner C, Lyles CR, Galvin G, Sabin J, Davis C, Dick A, et al. A qualitative assessment of personal and social responsibility for kidney disease: the increasing kidney disease awareness network transplant project. J Natl Med Assoc. 2011;103(9-10):879-84.

94. Brar A, Babakhani A, Salifu MO, Jindal RM. Evaluation of non-adherence in patients undergoing dialysis and kidney transplantation: United States transplantation practice patterns survey. Transplant Proc. 2014;46(5):1340-6.

95. Nonterah CW, Gardiner HM. Pre-transplant evaluation completion for Black/African American renal patients: two theoretical frameworks. Patient Educ Couns. 2020;103(5):988-98.

96. Kutner NG, Johansen KL, Zhang R, Huang Y, Amaral S. Perspectives on the new kidney disease education benefit: early awareness, race and kidney transplant access in a USRDS study. Am J Transplant. 2012;12(4):1017-23

97. Dageforde LA, Box A, Feurer ID, Cavanaugh KL. Understanding patient barriers to kidney transplant evaluation. Transplantation. 2015;99(7):1463-9.

98. Coorey GM, Paykin C, Singleton-Driscoll LC, Gaston RS. Barriers to preemptive kidney transplantation. Am J Nurs. 2009;109(11):28-37 quiz 8.

99. Browne T, Amamoo A, Patzer RE, Krisher J, Well H, Gander J, et al. Everybody needs a cheerleader to get a kidney transplant: a qualitative study of the patient barriers and facilitators to kidney transplantation in the southeastern United States. BMC Nephrol. 2016;17(1):108.

100. Lockwood MB, Saunders MR, Nass R, McGivern CL, Cunningham PN, Chon WJ, et al. Patient-reported barriers to the prekidney transplant evaluation in an at-risk population in the United States. Prog Transplant. 2017;27(2):131-8

101. Keddis M, Finnie D, Kim WS. Native American patients' perception and attitude about kidney transplant: a qualitative assessment of patients presenting for kidney transplant evaluation. BMJ Open. 2019;9(1):e024671.

102. Gillespie A, Hammer H, Lee J, Nnewihe C, Gordon J, Silva P. Lack of listing status awareness: results of a single-center survey of hemodialysis patients. Am J Transplant. 2011:11(7):1522-6.

103. Holley JL, McCauley C, Doherty B, Stackiewicz L, Johnson JP. Patients' views in the choice of renal transplant. Kidney Int. 1996;49(2):494-8.

104. Davis LA, Grogan TM, Cox J, Weng FL. Inter- and intrapersonal barriers to living donor kidney transplant among Black recipients and donors. J Racial Ethn Health Disparities. 2017;4(4):671-9. 
105. Klassen AC, Hall AG, Saksvig B, Curbow B, Klassen DK. Relationship between patients' perceptions of disadvantage and discrimination and listing for kidney transplantation. Am J Public Health. 2002;92(5):811-7.

106. Bittermann T, Dwinnells K, Chadha S, Wolf MS, Olthoff KM, Serper M. Low health literacy is associated with frailty and reduced likelihood of liver transplant listing: a prospective cohort study. Liver Transpl. 2020;26(11):1409-21.

107. Bababekov YJ, Hung YC, Rickert CG, Njoku FC, Cao B, Adler JT, et al. Health literacy burden is associated with access to liver transplantation. Transplantation. 2019;103(3):522-8.

108. Eckhoff DE, McGuire BM, Young CJ, Sellers MT, Frenette LR, Hudson $S L$, et al. Race: a critical factor in organ donation, patient referral and selection, and orthotopic liver transplantation? Liver Transpl Surg. 1998;4(6):499-505.

109. Reid AE, Resnick M, Chang Y, Buerstatte N, Weissman JS. Disparity in use of orthotopic liver transplantation among blacks and whites. Liver Transpl. 2004;10(7):834-41.

110. Rosenblatt R, Wahid N, Halazun KJ, Kaplan A, Jesudian A, Lucero C, et al. Black patients have unequal access to listing for liver transplantation in the United States. Hepatology. 2021:74:1523.

111. Jesse MT, Abouljoud M, Goldstein ED, Rebhan N, Ho CX, Macaulay T, et al. Racial disparities in patient selection for liver transplantation: an ongoing challenge. Clin Transpl. 2019;33(11):e13714.

112. Alshuwaykh O, Kwong A, Goel A, Cheung A, Dhanasekaran R, Ahmed $A$, et al. Predictors of outcomes of patients referred to a transplant center for urgent liver transplantation evaluation. Hepatol Commun. 2021;5(3):516-25

113. Dakhoul L, Gawrieh S, Jones KR, Ghabril M, McShane C, Orman E, et al. Racial disparities in liver transplantation for hepatocellular carcinoma are not explained by differences in comorbidities, liver disease severity, or tumor burden. Hepatol Commun. 2019;3(1):52-62.

114. Barritt AS, Telloni SA, Potter CW, Gerber DA, Hayashi PH. Local access to subspecialty care influences the chance of receiving a liver transplant. Liver Transpl. 2013;19(4):377-82.

115. John BV, Love E, Dahman B, Kurbanova N, Konjeti VR, Sundaram LT, et al. Use of telehealth expedites evaluation and listing of patients referred for liver transplantation. Clin Gastroenterol Hepatol. 2020;18(8):1822-30 e4.

116. Wilder JM, Oloruntoba OO, Muir AJ, Moylan CA. Role of patient factors, preferences, and distrust in health care and access to liver transplantation and organ donation. Liver Transpl. 2016;22(7):895-905.

117. Isaacs RB, Lobo PI, Nock SL, Hanson JA, Ojo AO, Pruett TL. Racial disparities in access to simultaneous pancreas-kidney transplantation in the United States. Am J Kidney Dis. 2000;36(3):526-33.

118. Melancon JK, Kucirka LM, Boulware LE, Powe NR, Locke JE, Montgomery RA, et al. Impact of Medicare coverage on disparities in access to simultaneous pancreas and kidney transplantation. Am J Transplant. 2009;9(12):2785-91.

119. Weng FL, Brown DR, Peipert JD, Holland B, Waterman AD. Protocol of a cluster randomized trial of an educational intervention to increase knowledge of living donor kidney transplant among potential transplant candidates. BMC Nephrol. 2013;14:256.

120. Weng FL, Peipert JD, Holland BK, Brown DR, Waterman AD. A clustered randomized trial of an educational intervention during transplant evaluation to increase knowledge of living donor kidney transplant. Prog Transplant. 2017;27(4):377-85.

121. Gordon EJ, Feinglass J, Carney P, Ramirez D, Olivero M, O'Connor K, et al. An interactive, bilingual, culturally targeted website about living kidney donation and transplantation for hispanics: development and formative evaluation. JMIR Res Protoc. 2015;4(2):e42.

122. Gordon EJ, Feinglass J, Carney P, Vera K, Olivero M, Black A, et al. A culturally targeted website for Hispanics/Latinos about living kidney donation and transplantation: a randomized controlled trial of increased knowledge. Transplantation. 2016;100(5):1149-60.

123. Gordon EJ, Feinglass J, Carney P, Vera K, Olivero M, Black A, et al. A website intervention to increase knowledge about living kidney donation and transplantation among Hispanic/Latino dialysis patients. Prog Transplant. 2016;26(1):82-91.

124. Patzer RE, McPherson L, Redmond N, DuBay D, Zayas C, Hartmann E, et al. A culturally sensitive web-based intervention to improve living donor kidney transplant among African Americans. Kidney Int Rep. 2019;4(9):1285-95.

125. Arriola KR, Powell CL, Thompson NJ, Perryman JP, Basu M. Living donor transplant education for African American patients with end-stage renal disease. Prog Transplant. 2014;24(4):362-70.

126. Weng FL, Davis LA, Ohman-Strickland PA, Waterman AD. Destination transplant: protocol for a parallel-group randomized trial of an educational intervention to increase kidney transplant among black people on the transplant waiting list. Transplant Direct. 2021;7(4):e683.

127. Waterman AD, Robbins ML, Paiva AL, Peipert JD, Kynard-Amerson CS, Goalby CJ, et al. Your path to transplant: a randomized controlled trial of a tailored computer education intervention to increase living donor kidney transplant. BMC Nephrol. 2014;15:166.

128. Boulware LE, Hill-Briggs F, Kraus ES, Melancon JK, McGuire R, Bonhage $B$, et al. Protocol of a randomized controlled trial of culturally sensitive interventions to improve African Americans' and non-African Americans' early, shared, and informed consideration of live kidney transplantation: the Talking About Live Kidney Donation (TALK) study. BMC Nephrol. 2011;12:34.

129. Rodrigue JR, Paek MJ, Egbuna O, Waterman AD, Schold JD, Pavlakis M, et al. Making house calls increases living donor inquiries and evaluations for blacks on the kidney transplant waiting list. Transplantation. 2014;98(9):979-86.

130. Rodrigue JR, Paek MJ, Egbuna O, Waterman AD, Schold JD, Pavlakis M, et al. Readiness of wait-listed black patients to pursue live donor kidney transplant. Prog Transplant. 2014;24(4):355-61.

131. Ephraim PL, Powe NR, Rabb H, Ameling J, Auguste P, Lewis-Boyer L, et al. The providing resources to enhance African American patients' readiness to make decisions about kidney disease (PREPARED) study: protocol of a randomized controlled trial. BMC Nephrol. 2012;13:135.

132. Boulware LE, Ephraim PL, Ameling J, Lewis-Boyer L, Rabb H, Greer $R C$, et al. Effectiveness of informational decision aids and a live donor financial assistance program on pursuit of live kidney transplants in African American hemodialysis patients. BMC Nephrol. 2018;19(1):107

133. Strigo TS, Ephraim PL, Pounds I, Hill-Briggs F, Darrell L, Ellis M, et al. The TALKS study to improve communication, logistical, and financial barriers to live donor kidney transplantation in African Americans: protocol of a randomized clinical trial. BMC Nephrol. 2015;16:160.

134. Bornemann $\mathrm{K}$, Croswell $\mathrm{E}$, Abaye $\mathrm{M}$, Bryce $\mathrm{CL}$, Chang $\mathrm{CH}$, Good DS, et al. Protocol of the KTFT-TALK study to reduce racial disparities in kidney transplant evaluation and living donor kidney transplantation. Contemp Clin Trials. 2017;53:52-9.

135. Gordon EJ, Lee J, Kang RH, Caicedo JC, Holl JL, Ladner DP, et al. A complex culturally targeted intervention to reduce Hispanic disparities in living kidney donor transplantation: an effectiveness-implementation hybrid study protocol. BMC Health Serv Res. 2018;18(1):368.

136. Bloembergen WE, Port FK, Mauger EA, Briggs JP, Leichtman AB. Gender discrepancies in living related renal transplant donors and recipients. J Am Soc Nephrol. 1996;7(8):1139-44.

137. Gore JL, Danovitch GM, Litwin MS, Pham PT, Singer JS. Disparities in the utilization of live donor renal transplantation. Am J Transplant. 2009:9(5):1124-33.

138. Ojo A, Port FK. Influence of race and gender on related donor renal transplantation rates. Am J Kidney Dis. 1993;22(6):835-41.

139. Purnell TS, Luo X, Cooper LA, Massie AB, Kucirka LM, Henderson ML, et al. Association of race and ethnicity with live donor kidney transplantation in the United States from 1995 to 2014. Jama. 2018;319(1):49-61.

140. Purnell TS, Xu P, Leca N, Hall YN. Racial differences in determinants of live donor kidney transplantation in the United States. Am J Transplant. 2013;13(6):1557-65.

141. Gander JC, Zhang X, Plantinga L, Paul S, Basu M, Pastan SO, et al. Racial disparities in preemptive referral for kidney transplantation in Georgia. Clin Transpl. 2018;32(9):e13380.

142. Kayler LK, Rasmussen CS, Dykstra DM, Ojo AO, Port FK, Wolfe RA, et al. Gender imbalance and outcomes in living donor renal transplantation in the United States. Am J Transplant. 2003;3(4):452-8.

143. Gill J, Dong J, Gill J. Population income and longitudinal trends in living kidney donation in the United States. J Am Soc Nephrol. 2015;26(1):201-7. 
144. Kasiske BL, Snyder JJ, Matas AJ, Ellison MD, Gill JS, Kausz AT. Preemptive kidney transplantation: the advantage and the advantaged. J Am Soc Nephrol. 2002;13(5):1358-64.

145. Hall EC, James NT, Garonzik Wang JM, Berger JC, Montgomery RA, Dagher NN, et al. Center-level factors and racial disparities in living donor kidney transplantation. Am J Kidney Dis. 2012;59(6):849-57.

146. Kumar K, Holscher CM, Luo X, Garonzik Wang J, Anjum S, King EA, et al. Persistent regional and racial disparities in nondirected living kidney donation. Clin Transpl. 2017:31(12):10.1111/ctr.13135.

147. Vilme H, Davenport CA, Pendergast J, Boulware LE. Trends in African Americans' attitudes and behaviors about living donor kidney transplantation. Prog Transplant. 2018;28(4):354-60.

148. Khosla N, Gordon E, Nishi L, Ghossein C. Impact of a chronic kidney disease clinic on preemptive kidney transplantation and transplant wait times. Prog Transplant. 2010;20(3):216-20.

149. Lunsford SL, Simpson KS, Chavin KD, Menching KJ, Miles LG, Shilling LM, et al. Racial disparities in living kidney donation: is there a lack of willing donors or an excess of medically unsuitable candidates? Transplantation. 2006;82(7):876-81.

150. Reeves-Daniel A, Adams PL, Daniel K, Assimos D, Westcott C, Alcorn SG, et al. Impact of race and gender on live kidney donation. Clin Transpl. 2009;23(1):39-46.

151. Weng FL, Reese PP, Mulgaonkar S, Patel AM. Barriers to living donor kidney transplantation among black or older transplant candidates. Clin J Am Soc Nephrol. 2010;5(12):2338-47.

152. Kumar K, Tonascia JM, Muzaale AD, Purnell TS, Ottmann SE, Al Ammary $F$, et al. Racial differences in completion of the living kidney donor evaluation process. Clin Transpl. 2018;32(7):e13291.

153. Rodrigue JR, Kazley AS, Mandelbrot DA, Hays R, LaPointe RD, Baliga P. Living donor kidney transplantation: overcoming disparities in live kidney donation in the US--recommendations from a consensus conference. Clin J Am Soc Nephrol. 2015;10(9):1687-95.

154. Waterman AD, Morgievich M, Cohen DJ, Butt Z, Chakkera HA, Lindower $C$, et al. Living donor kidney transplantation: improving education outside of transplant centers about live donor transplantation--recommendations from a consensus conference. Clin J Am Soc Nephrol. 2015;10(9):1659-69.

155. Mclntosh T, Mohan S, Sawinski D, Iltis A, DuBois JM. Variation of ApoL1 testing practices for living kidney donors. Prog Transplant. 2020;30(1):22-8.

156. Gupta N, Salter ML, Garonzik-Wang JM, Reese PP, Wickliffe CE, Dagher NN, et al. Actual and perceived knowledge of kidney transplantation and the pursuit of a live donor. Transplantation. 2014;98(9):969-73.

157. Griffin LW, Bratton LB. Fewer black kidney donors: what's the problem? Soc Work Health Care. 1995;22(2):19-42.

158. Adams-Leander $\mathrm{S}$. The experiences of African-American living kidney donors. Nephrol Nurs J. 2011;38(6):499-508 quiz 9.

159. McDonald EL, Powell CL, Perryman JP, Thompson NJ, Arriola KR. Understanding the relationship between trust in health care and attitudes toward living donor transplant among African Americans with endstage renal disease. Clin Transpl. 2013;27(4):619-26.

160. Brick LA, Sorensen D, Robbins ML, Paiva AL, Peipert JD, Waterman AD. Invariance of measures to understand decision-making for pursuing living donor kidney transplant. J Health Psychol. 2016;21(12):2912-22.

161. Gillespie A, Hammer H, Kolenikov S, Polychronopoulou A, Ouzienko V, Obradovic Z, et al. Sex differences and attitudes toward living donor kidney transplantation among urban black patients on hemodialysis. Clin J Am Soc Nephrol. 2014;9(10):1764-72.

162. Gillespie A, Gardiner HM, Fink EL, Reese PP, Gadegbeku CA, Obradovic Z. Does sex, race, and the size of a kidney transplant candidate's social network affect the number of living donor requests? A multicenter social network analysis of patients on the kidney transplant waitlist. Transplantation. 2020;104(12):2632-41.

163. Siegel JT, O'Brien EK, Alvaro EM, Poulsen JA. Barriers to living donation among low-resource Hispanics. Qual Health Res. 2014;24(10):1360-7.

164. Nobel YR, Forde KA, Wood L, Cartiera K, Munoz-Abraham AS, Yoo PS, et al. Racial and ethnic disparities in access to and utilization of living donor liver transplants. Liver Transpl. 2015:21(7):904-13.

165. Doyle A, Rabie RN, Mokhtari A, Cattral M, Ghanekar A, Grant D, et al. Recipient factors associated with having a potential living donor for liver transplantation. Liver Transpl. 2015;21(7):897-903.
166. Cotler SJ, McNutt R, Patil R, Banaad-Omiotek G, Morrissey M, Abrams R, et al. Adult living donor liver transplantation: preferences about donation outside the medical community. Liver Transpl. 2001;7(4):335-40.

167. Singh TP, Almond CS, Taylor DO, Milliren CE, Graham DA. Racial and ethnic differences in wait-list outcomes in patients listed for heart transplantation in the United States. Circulation. 2012;125(24):3022-30.

168. Coughlin SS, Halabi S, Metayer C. Barriers to cardiac transplantation in idiopathic dilated cardiomyopathy: the Washington, DC, dilated cardiomyopathy study. J Natl Med Assoc. 1998;90(6):342-8.

169. Frech A, Tarrence J, Natale G, Tumin D. Ventricular assist device technology and black-white disparities on the heart transplant wait list. Prog Transplant. 2021;31(1):80-7.

170. Okoh AK, Selevanny M, Singh S, Hirji S, Singh S, Al Obaidi N, et al. Racial disparities and outcomes of left ventricular assist device implantation as a bridge to heart transplantation. ESC Heart Fail. 2020;7(5):2744-51.

171. DeFilippis EM, Truby LK, Garan AR, Givens RC, Takeda K, Takayama $\mathrm{H}$, et al. Sex-related differences in use and outcomes of left ventricular assist devices as bridge to transplantation. JACC Heart Fail. 2019;7(3):250-7.

172. Smith SA, Hasan AK, Binkley PF, Foraker RE. The impact of insurance and socioeconomic status on outcomes for patients with left ventricular assist devices. J Surg Res. 2014;191(2):302-8.

173. Clerkin KJ, Garan AR, Wayda B, Givens RC, Yuzefpolskaya M, Nakagawa $\mathrm{S}$, et al. Impact of socioeconomic status on patients supported with a left ventricular assist device: an analysis of the UNOS database (united network for organ sharing). Circulation. 2016;9(10):e003215.

174. Emani S, Tumin D, Foraker RE, Hayes D Jr, Smith SA. Impact of insurance status on heart transplant wait-list mortality for patients with left ventricular assist devices. Clin Transpl. 2017;31(2):10.1111/ctr.12875.

175. Wesselman H, Ford CG, Leyva Y, Li X, Chang CH, Dew MA, et al. Social determinants of health and race disparities in kidney transplant. Clin J Am Soc Nephrol. 2021;16(2):262-74.

176. Mathur AK, Ashby VB, Sands RL, Wolfe RA. Geographic variation in endstage renal disease incidence and access to deceased donor kidney transplantation. Am J Transplant. 2010;10(4 Pt 2):1069-80.

177. Plantinga L, Pastan S, Kramer M, McClellan A, Krisher J, Patzer RE. Association of U.S. Dialysis facility neighborhood characteristics with facility-level kidney transplantation. Am J Nephrol. 2014;40(2):164-73.

178. Mohan S, Mutell R, Patzer RE, Holt J, Cohen D, McClellan W. Kidney transplantation and the intensity of poverty in the contiguous United States. Transplantation. 2014;98(6):640-5.

179. Ozminkowski RJ, White AJ, Hassol A, Murphy M. What if socioeconomics made no difference?: access to a cadaver kidney transplant as an example. Med Care. 1998;36(9):1398-406.

180. Grams ME, Chen BP, Coresh J, Segev DL. Preemptive deceased donor kidney transplantation: considerations of equity and utility. Clin J Am Soc Nephrol. 2013;8(4):575-82.

181. Kutner NG, Zhang R, Huang Y, Johansen KL. Impact of race on predialysis discussions and kidney transplant preemptive wait-listing. Am J Nephrol. 2012;35(4):305-11.

182. Harhay MN, Harhay MO, Ranganna K, Boyle SM, Levin Mizrahi L, Guy S, et al. Association of the kidney allocation system with dialysis exposure before deceased donor kidney transplantation by preemptive waitlisting status. Clin Transpl. 2018;32(10):e13386.

183. Taber DJ, DuBay D, McGillicuddy JW, Nadig S, Bratton CF, Chavin $\mathrm{KD}$, et al. Impact of the new kidney allocation system on perioperative outcomes and costs in kidney transplantation. J Am Coll Surg. 2017;224(4):585-92.

184. King KL, Husain SA, Jin Z, Brennan C, Mohan S. Trends in disparities in preemptive kidney transplantation in the United States. Clin J Am Soc Nephrol. 2019;14(10):1500-11.

185. Ku E, McCulloch CE, Adey DB, Li L, Johansen KL. Racial disparities in eligibility for preemptive waitlisting for kidney transplantation and modification of eGFR thresholds to equalize waitlist time. J Am Soc Nephrol. 2021;32(3):677-85.

186. Melanson TA, Hockenberry JM, Plantinga L, Basu M, Pastan S, Mohan $S$, et al. New kidney allocation system associated with increased rates of transplants among black and hispanic patients. Health Aff (Millwood). 2017;36(6):1078-85.

187. King KL, Husain SA, Schold JD, Patzer RE, Reese PP, Jin Z, et al. Major variation across local transplant centers in probability 
of kidney transplant for wait-listed patients. J Am Soc Nephrol. 2020;31(12):2900-11.

188. Newman KL, Fedewa SA, Jacobson MH, Adams AB, Zhang R, Pastan $S O$, et al. Racial/ethnic differences in the association between hospitalization and kidney transplantation among waitlisted end-stage renal disease patients. Transplantation. 2016;100(12):2735-45.

189. Kulkarni S, Ladin K, Haakinson D, Greene E, Li L, Deng Y. Association of racial disparities with access to kidney transplant after the implementation of the new kidney allocation system. JAMA Surg. 2019;154(7):618-25.

190. Vranic GM, Ma JZ, Keith DS. The role of minority geographic distribution in waiting time for deceased donor kidney transplantation. Am J Transplant. 2014;14(11):2526-34.

191. Schold JD, Kaplan B, Chumbler NR, Howard RJ, Srinivas TR, Ma L, et al. Access to quality: evaluation of the allocation of deceased donor kidneys for transplantation. J Am Soc Nephrol. 2005;16(10):3121-7.

192. Hall YN, Choi Al, Xu P, O'Hare AM, Chertow GM. Racial ethnic differences in rates and determinants of deceased donor kidney transplantation. J Am Soc Nephrol. 2011;22(4):743-51.

193. Arce CM, Goldstein BA, Mitani AA, Lenihan CR, Winkelmayer WC. Differences in access to kidney transplantation between Hispanic and non-Hispanic whites by geographic location in the United States. Clin J Am Soc Nephrol. 2013;8(12):2149-57.

194. Whelan AM, Johansen KL, Brar S, McCulloch CE, Adey DB, Roll GR, et al. Association between longer travel distance for transplant care and access to kidney transplantation and graft survival in the United States. J Am Soc Nephrol. 2021;32(5):1151-61.

195. Gill JS, Hussain S, Rose C, Hariharan S, Tonelli M. Access to kidney transplantation among patients insured by the United States Department of Veterans Affairs. J Am Soc Nephrol. 2007;18(9):2592-9.

196. Harris TT, Thomas CM, Wicks MN, Faulkner MS, Hathaway DK. Subjective burden in young and older African-American caregivers of patients with end stage renal disease awaiting transplant. Nephrol Nurs J. 2000;27(4):383-91, 55; discussion 92, 405.

197. Joshi S, Gaynor JJ, Bayers S, Guerra G, Eldefrawy A, Chediak Z, et al. Disparities among blacks, hispanics, and whites in time from starting dialysis to kidney transplant waitlisting. Transplantation. 2013;95(2):309-18.

198. Ozminkowski RJ, White AJ, Hassol A, Murphy M. Minimizing racial disparity regarding receipt of a cadaver kidney transplant. Am J Kidney Dis. 1997;30(6):749-59.

199. Rubin JB, Srisengfa YT, Albhaisi S, Acharya C, Nangia G, Shaikh T, et al. Hospitalized women with cirrhosis have more nonhepatic comorbidities and associated complications than men. Clin Gastroenterol Hepatol. 2020;18(13):3046-8.

200. Rubin JB, Sinclair M, Rahimi RS, Tapper EB, Lai JC. Women on the liver transplantation waitlist are at increased risk of hospitalization compared to men. World J Gastroenterol. 2019;25(8):980-8.

201. Argo CK, Stukenborg GJ, Schmitt TM, Kumer SC, Berg CL, Northup PG. Regional variability in symptom-based MELD exceptions: a response to organ shortage? Am J Transplant. 2011;11(11):2353-61.

202. Bababekov YJ, Hung YC, Chang DC, Rickert CG, Adler JT, Bethea E, et al. Do social determinants define "too sick" to transplant in patients with end-stage liver disease? Transplantation. 2020;104:280-4.

203. Muir AJ, Sanders LL, Heneghan MA, Kuo PC, Wilkinson WE, Provenzale D. An examination of factors predicting prioritization for liver transplantation. Liver Transpl. 2002;8(10):957-61.

204. Ahn J, Liu B, Bhuket T, Wong RJ. Race/ethnicity-specific outcomes among chronic hepatitis $C$ virus patients listed for liver transplantation. Dig Dis Sci. 2017;62(4):1051-7.

205. Allen JG, Weiss ES, Arnaoutakis GJ, Russell SD, Baumgartner WA, Conte JV, et al. The impact of race on survival after heart transplantation: an analysis of more than 20,000 patients. Ann Thorac Surg. 2010;89(6):1956-64.

206. Cholankeril G, Gonzalez HC, Satapathy SK, Gonzalez SA, Hu M, Khan MA, et al. Increased waitlist mortality and lower rate for liver transplantation in Hispanic patients with primary biliary cholangitis. Clin Gastroenterol Hepatol. 2018;16(6):965-73.e2.

207. Cullaro G, Sarkar M, Lai JC. Sex-based disparities in delisting for being "too sick" for liver transplantation. Am J Transplant. 2018;18(5):1214-9.
208. Kaswala DH, Zhang J, Liu A, Sundaram V, Liu B, Bhuket T, et al. A comprehensive analysis of liver transplantation outcomes among ethnic minorities in the United States. J Clin Gastroenterol. 2020;54(3):263-70.

209. Lai JC, Terrault NA, Vittinghoff E, Biggins SW. Height contributes to the gender difference in wait-list mortality under the MELD-based liver allocation system. Am J Transplant. 2010;10(12):2658-64.

210. Locke JE, Shelton BA, Olthoff KM, Pomfret EA, Forde KA, Sawinski D, et al. Quantifying sex-based disparities in liver allocation. JAMA Surg. 2020;155(7):e201129.

211. Mathur AK, Schaubel DE, Gong Q, Guidinger MK, Merion RM. Racial and ethnic disparities in access to liver transplantation. Liver Transpl. 2010;16(9):1033-40.

212. Mathur AK, Schaubel DE, Gong Q, Guidinger MK, Merion RM. Sex-based disparities in liver transplant rates in the United States. Am J Transplant. 2011;11(7):1435-43.

213. Mindikoglu AL, Emre SH, Magder LS. Impact of estimated liver volume and liver weight on gender disparity in liver transplantation. Liver Transpl. 2013;19(1):89-95.

214. Mindikoglu AL, Regev A, Seliger SL, Magder LS. Gender disparity in liver transplant waiting-list mortality: the importance of kidney function. Liver Transpl. 2010;16(10):1147-57.

215. Moylan CA, Brady CW, Johnson JL, Smith AD, Tuttle-Newhall JE, Muir AJ. Disparities in liver transplantation before and after introduction of the MELD score. Jama. 2008;300(20):2371-8.

216. Mustian MN, Shelton BA, MacLennan PA, Reed RD, White JA, Eckhoff $\mathrm{DE}$, et al. Ethnic and age disparities in outcomes among liver transplant waitlist candidates. Transplantation. 2019;103(7):1425-32.

217. Quillin RC 3rd, Wilson GC, Wima K, Hohmann SF, Sutton JM, Shaw JJ, et al. Neighborhood level effects of socioeconomic status on liver transplant selection and recipient survival. Clin Gastroenterol Hepatol. 2014;12(11):1934-41.

218. Robinson A, Hirode G, Wong RJ. Ethnicity and insurance-specific disparities in the model for end-stage liver disease score at time of liver transplant waitlist registration and its impact on mortality. J Clin Exp Hepatol. 2021;11(2):188-94.

219. Ross K, Patzer RE, Goldberg DS, Lynch RJ. Sociodemographic determinants of waitlist and posttransplant survival among end-stage liver disease patients. Am J Transplant. 2017;17(11):2879-89.

220. Smith AA, Darden M, Al-Qurayshi Z, Paramesh AS, Killackey M, Kandil E, et al. Liver transplantation in New Orleans: parity in a world of disparity? HPB (Oxford). 2017;19(9):793-8.

221. Thuluvath PJ, Amjad W, Zhang T. Liver transplant waitlist removal, transplantation rates and post-transplant survival in Hispanics. PLoS One. 2020;15(12):e0244744.

222. Wong RJ, Devaki P, Nguyen L, Cheung R, Nguyen MH. Ethnic disparities and liver transplantation rates in hepatocellular carcinoma patients in the recent era: results from the surveillance, epidemiology, and end results registry. Liver Transpl. 2014;20(5):528-35.

223. Zhang Y. The impact of the share 35 policy on racial and ethnic disparities in access to liver transplantation for patients with end stage liver disease in the United States: an analysis from UNOS database. Int J Equity Health. 2017;16(1):55.

224. Gutin L, Yao F, Dodge JL, Grab J, Mehta N. Comparison of liver transplant wait-list outcomes among patients with hepatocellular carcinoma with public vs private medical insurance. JAMA Netw Open. 2019;2(8):e1910326-e.

225. Kohn R, Kratz JR, Markmann JF, Vagefi PA. The migrated liver transplantation candidate: insight into geographic disparities in liver distribution. J Am Coll Surg. 2014;218(6):1113-8.

226. Beal EW, Tumin D, Sobotka L, Tobias JD, Hayes D Jr, PawlikTM, et al. Patients from appalachia have reduced access to liver transplantation after wait-listing. Prog Transplant. 2018;28(4):305-13.

\section{Publisher's Note}

Springer Nature remains neutral with regard to jurisdictional claims in published maps and institutional affiliations. 